Nervenarzt 2020 $911: 722-734$

https://doi.org/10.1007/s00115-020-00937-6

Online publiziert: 10. Juni 2020

(c) Der/die Autor(en) 2020

Jonas Graf · Philipp Albrecht · Norbert Goebels · Orhan Aktas · Hans-Peter Hartung

Klinik für Neurologie, Universitätsklinikum Düsseldorf, Medizinische Fakultät, Heinrich-Heine-Universität, Düsseldorf, Deutschland

\title{
Ocrelizumab zur Behandlung der Multiplen Sklerose
}

folgepräparate mit ähnlichem Wirkprofil [8] in der klinischen Entwicklung befinden bzw. gerade zugelassen wurden (z.B. der oral applizierte BrutonTyrosin-Kinase-Hemmer Evobrutinib [9] NCT04032158 und die monoklonalen Antikörper Ofatumumab [10] NCT02792218 bzw. NCT02792231, Ublituximab NCT03277261 bzw. NCT0327 7248 und NCT04032171). Die Ergebnisse der Ofatumumab-Zulassungsstudien wurden 2019 auf dem ECTRIMS-Kongress präsentiert. Ofatumumab führte $\mathrm{zu}$ einer relativen Risikoreduktion von 50,5\% (ASCLEPIOS I) bzw. 58,5\% (ASCLEPIOS II) der auf ein Jahr umgerechneten Schubrate im Vergleich zu Teriflunomid [11]. Die Substanz wurde gut vertragen.

Interessanterweise führen niedrig dosierte intrathekale Gaben von Rituximab zu einer kompletten CD20-Depletion im peripheren Blut [12], jedoch zu keiner vollständigen CD20-Depletion im ZNS [13]. Diese therapeutischen Entwicklungen haben dazu beigetragen, unsere Konzepte der pathophysiologischen Rolle der Immunzellen in der MS wesentlich $\mathrm{zu}$ wandeln [14].

Aktuell geht man davon aus, dass B-Zellen - und nicht mehr ausschließlich oder dominant T-Zellen - eine zentrale Bedeutung in der MS zukommt (- Abb. 2, adaptiert aus [14]). - Tab. 1 fasst die Rolle von B-Zellen in der Pathophysiologie der MS zusammen.

\section{Rituximab bei RRMS und PPMS: Fallberichte und -serien}

Die ersten Berichte über den Einsatz von CD20-Depletion bei Patienten mit Multipler Sklerose stammen aus den Jahren
2005 und 2006. In einer ersten Fallserie von PPMS-Patienten wurde zunächst das B-Zell-Muster sowohl im peripheren Blut als auch im Liquor vor und nach Gabe von Rituximab untersucht. Erwartungsgemäß depletierte Rituximab B-Zellen im peripheren Blut rasch, effektiv und längerfristig, die Wirkung auf B-Zellen im Liquor war jedoch gering ausgeprägt. Auch konnte gezeigt werden, dass die Kinetik der B-Zell-Repopulation individuell bei Patienten deutlich schwanken kann [15]. Diese Ergebnisse stehen teilweise im Widerspruch zu einer weiteren Fallserie, bei der Rituximab als Zusatztherapie bei RRMS-Patienten verabreicht wurde: Bei diesen Patienten zeigte sich ein Abfall von sowohl B- als auch T-Lymphozyten im Liquor [16]. Bei einem anderen RRMS-Patienten mit fulminantem

\begin{tabular}{l} 
Tab. 1 Hinweise auf die möglichen patho- \\
physiologischen Rollen von B-Lymphozyten \\
bei der Multiplen Sklerose \\
Intrathekale Produktion von Immunglobuli- \\
nen (oligoklonale Banden) \\
Produktion von Antikörpern gegen Myelin- \\
bestandteile in Blut und Liquor \\
B-Zell- und Komplementablagerungen in \\
Hirnläsionen \\
Meningeale B-Zell-Aggregate bei SPMS \\
Expandierte Plasmablasten in Blut und \\
Liquor \\
Antigenpräsentation, Zytokinproduktion, \\
Förderung des "homing“ autoreaktiver \\
T-Zellen ins ZNS \\
Induktion und Regulation der Proliferation \\
autoreaktiver, proinflammatorischer T-Zel- \\
len (u. a. TH17-Zellen) \\
\hline Induktion der Apoptose von Neuronen und \\
Oligodendrozyten \\
\hline SPMS Sekundär progrediente Multiple Skle- \\
rose
\end{tabular}




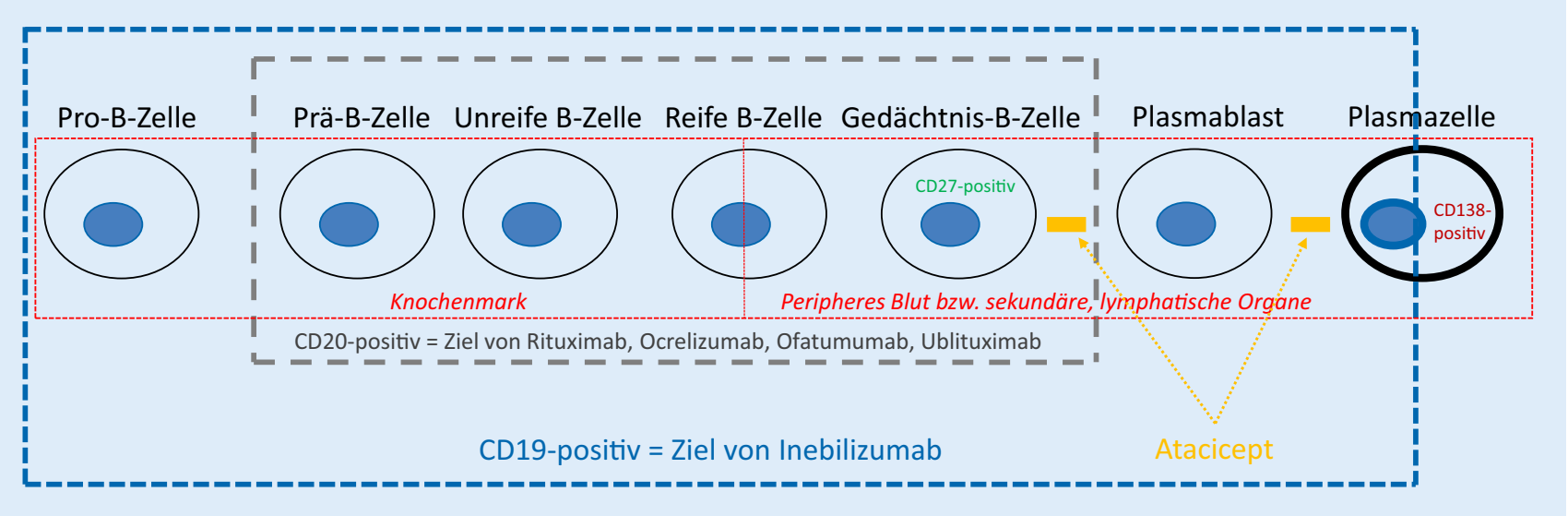

Abb. 1 \ Zelluläre Ziele der CD20-Depletion. Während der B-Zell-Reifung werden unterschiedliche Differenzierungsantigene auf der Oberfläche der Zellen exprimiert, die von den therapeutisch eingesetzten monoklonalen Antikörpern erkannt werden. Die Bindung führt schließlich über antikörper- oder komplementabhängige zytotoxische Mechanismen zur Depletion. Von Bedeutung ist, dass die frühesten und spätesten Reifungsstufen wegen fehlender CD20-Expression nicht depletiert werden. Somit ist die Fähigkeit zur B-Zell-Repopulation erhalten sowie auch das humorale Immungedächtnis unbeeinträchtigt. Dadurch werden natürliche Abwehrmechanismen in ihrer Funktionalität bewahrt. Atacicept ist ein Wirkstoff, der die Differenzierung der B-Zelle hemmt. Atacicept ist ein rekombinantes Fusionsprotein, welches zwei für B-Zell-Reifung, -Funktion und -Überleben notwendige Zytokine, „B-lymphocyte stimulator" (BlyS) und „A proliferation-inducing ligand“ (APRIL), über den Fc-Teil von Immunglobulin bindet und somit neutralisiert. (Adaptiert aus [7])

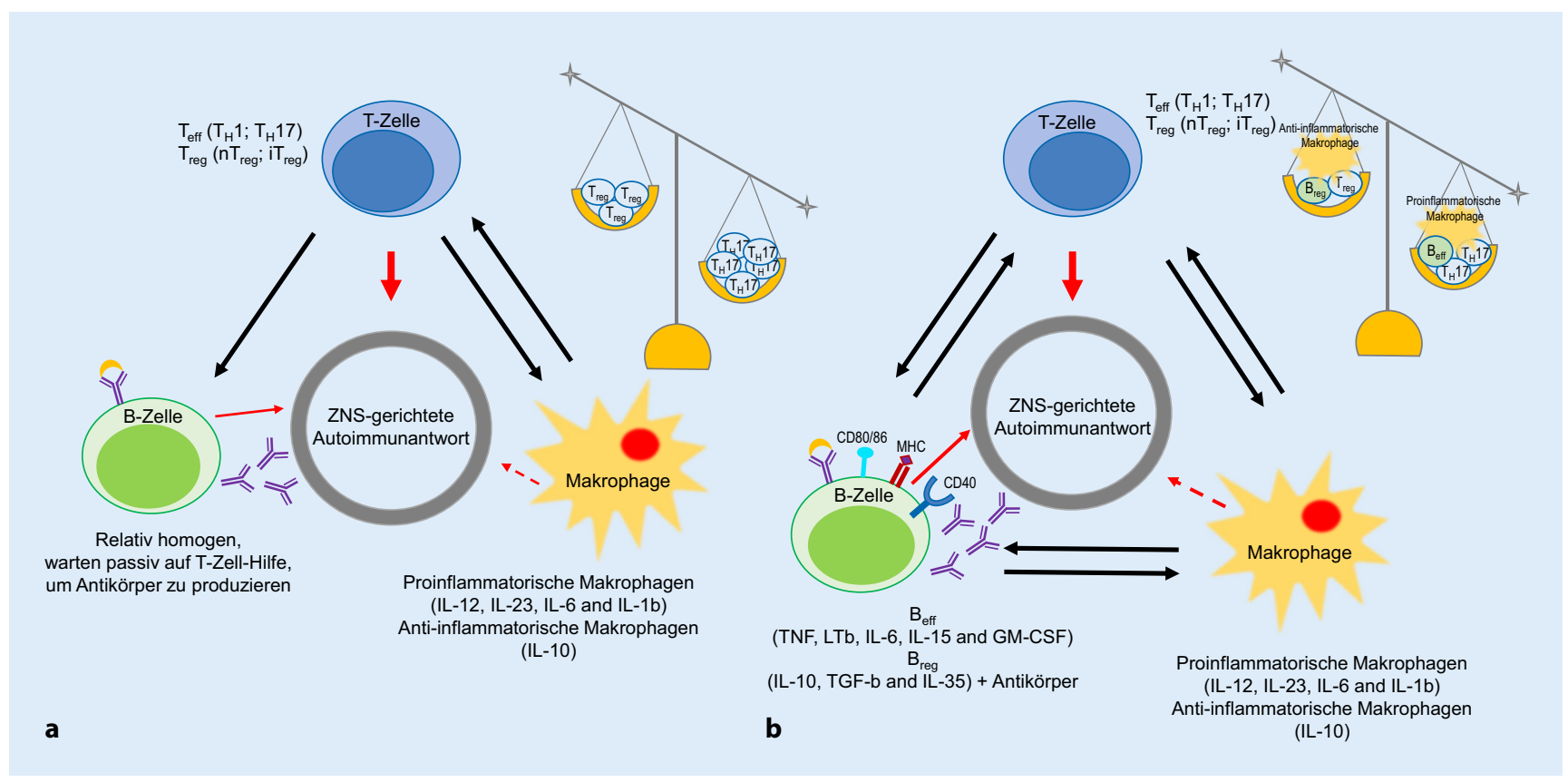

Abb. 2 \ Hypothesen zur Rolle von Immunzellen bei der Multiplen Sklerose (MS) im Wandel. a Traditionell war man der Ansicht, dass T-Zellen eine primäre zentrale Bedeutung in der Pathophysiologie der MS haben. MS-Schübe stehen im Zusammenhang mit einem Missverhältnis zwischen proinflammatorischen $T_{H} 1$-Helferzellen und $T_{H} 17$-Effektor-T-Zellen $\left(T_{\text {eff }}\right)$ und

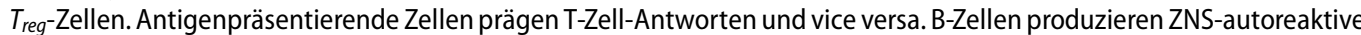
Antikörper. b Aktuell ist man der Ansicht, dass B-Zellen eine zentrale Rolle in der Pathophysiologie der MS einnehmen, die wahrscheinlich sowohl antikörpervermittelt als auch antikörperunabhängig ist. Zytokinvermittelte Immunantworten von proinflammatorischen B-Effektorzellen $\left(B_{\text {eff }}\right)$ oder antiinflammatorischen, regulatorischen B-Zellen $\left(B_{\text {reg }}\right)$, die sich gegenseitig beeinflussen und sowohl antigenpräsentierende Zellen, als auch T-Zellen regulieren, scheinen im Mittelpunkt zu stehen. IL Interleukin, TNF Tumornekrosefaktor, TGF Transforming growth factor, GM-CSF Granulozyten-Monozyten-Kolonie-stimulierende Faktor, ZNS Zentralnervensystem. (Modifiziert nach [14]) 
Krankheitsverlauf kam es nach intravenöser Gabe von Rituximab nicht nur zum Stillstand der Erkrankung, sondern auch zu Besserungen des klinischen Funktionsstatus [17-19].

\section{Rituximab bei RRMS: Phase-1- und-2-Studien}

Eine nichtkontrollierte „Open-label“Phase-1-Studie mit 26 RRMS-Patienten belegte ein günstiges Sicherheitsprofil von Rituximab über 72 Wochen. Der Antikörper verminderte die Anzahl neu aufgetretener Hirnläsionen zwischen Woche 4 und 72 und reduzierte die Schubrate im Vergleich zum Jahr vor Studienbeginn [20]. Die anschließende, doppelblinde, placebokontrollierte Phase-2-Studie (HERMES, - Tab. 2) konnte dokumentieren, dass Rituximab nicht nur im primären magnetresonanztomographischen (MRT-) Endpunkt, sondern auch in den sekundären klinischen Zielkriterien gegenüber Placebo überlegen war [21].

\section{Rituximab bei PPMS: Phase-2/3-Studie}

Aufgrund der überraschend guten Wirksamkeit der CD20-Depletion bei Patienten mit schubförmiger Multipler Sklerose wuchs die Hoffnung, dass dieser therapeutische Ansatz ebenfalls einen positiven Einfluss auf den primär chronischprogredienten Krankheitsverlauf haben könnte. Die randomisierte, doppelblinde, placebokontrollierte Phase-2/3-OLYMPUS-Studie bei PPMS (- Tab. 2) verfehlte jedoch den primären klinischen Endpunkt: Es konnte kein signifikanter Unterschied in der Wirksamkeit auf die bestätigte Behinderungsprogression nachgewiesen werden. Doch der sekundäre radiologische Endpunkt, die signifikante Reduktion der T2-Läsionslast, wurde erreicht und Subgruppenanalysen zeigten, dass insbesondere jüngere Patienten, die im MRT aktive entzündliche Läsionen aufweisen, auch klinisch von einer Therapie mit Rituximab profitierten $[22,23]$.

Nervenarzt 2020 $91: 722-734$ https://doi.org/10.1007/s00115-020-00937-6

(c) Der/die Autor(en) 2020

\section{J. Graf · P. Albrecht · N. Goebels · O. Aktas · H.-P. Hartung}

\section{Ocrelizumab zur Behandlung der Multiplen Sklerose}

\section{Zusammenfassung}

Ocrelizumab ist ein monoklonaler Antikörper, der sich gegen das Differenzierungsantigen $\mathrm{CD} 20$ richtet und zu einer effektiven längerfristigen Depletion von Lymphozyten, insbesondere von B-Zellen, führt. Unlängst publizierte Phase-3-Studien belegen, dass Ocrelizumab sowohl bei der Behandlung der schubförmigen als auch der primär progressiven Multiplen Sklerose (MS) wirksam ist. Darauf basierend wurde Ocrelizumab als erstes Medikament zur Behandlung der primär chronisch-progredienten MS zugelassen. Um diesen Durchbruch besser in den Kontext des heutigen MSTherapiekanons einordnen zu können, lohnt sowohl ein Blick zurück auf die Entwicklung der antikörpervermittelten CD20-Depletion als auch auf die der Zulassung zugrunde liegenden Studien sowie deren Extensionsphasen. Diese Übersichtsarbeit diskutiert die verfügbaren Daten zur Wirksamkeit und Sicherheit der langfristigen B-Zell-Depletion bei MS-Patienten und erörtert den aktuellen Kenntnisstand zur Rolle von B-Lymphozyten in der Immunpathogenese der MS.

Schlüsselwörter

B-Zell-depletierende monoklonale Antikörper · B-Zellen · Immunsuppression · Klinische Neuroimmunologie $\cdot$ Neuroinflammation

\section{Ocrelizumab for treatment of multiple sclerosis}

\section{Abstract}

Ocrelizumab is a monoclonal antibody directed against the differentiation antigen CD20, which leads to an effective longterm depletion of lymphocytes, in particular $B$ cells. Recently published phase 3 studies confirmed that ocrelizumab is effective in the treatment of both relapsing multiple sclerosis (RMS) and primary progressive multiple sclerosis (PPMS). Based on these results, ocrelizumab was the first drug to be approved for primary chronic progressive MS. To place this therapeutic breakthrough in the context of the current MS therapeutic landscape, it is worthwhile taking a look back at the development of antibody-mediated CD20 depletion, the studies underlying the approval of ocrelizumab and their open extension phases. This review article discusses the available data on the efficacy and safety of long-term B-cell depletion in MS patients and reviews current knowledge on the role of B-lymphocytes in the immunopathogenesis of MS.

\section{Keywords}

B cell depleting monoclonal antibodies B cells - Immunosuppression · Clinical neuroimmunology $\cdot$ Neuroinflammation

\section{Ocrelizumab: RRMS-Phase- 2-, RRMS-Phase-3- und PPMS-Phase-3-Studien sowie Folgestudien nach Zulassung}

In den folgenden Studien zur Wirksamkeit der CD20-Depletion bei MSPatienten wurde nun nicht mehr der chimäre monoklonale Antikörper Rituximab, sondern der strukturell humanisierte Antikörper Ocrelizumab verwendet (•Tab. 3). Die randomisierte, doppelt verblindete Phase-2-Studie mit Interferon- $\beta_{1 \mathrm{a}}$ (IFN- $\beta_{1 \mathrm{a}} 30 \mu \mathrm{g}$ pro Woche intramuskulär) als aktivem Komparator zeigte die Überlegenheit von Ocrelizumab hinsichtlich des radiologisch definierten primären Endpunktes (An- zahl der gadoliniumaufnehmenden T1Läsionen im der zerebralen MRT). Hinsichtlich der Nebenwirkungen zeigte sich kein relevanter Unterschied zwischen den einzelnen Gruppen [24].

Zur Zulassung von Ocrelizumab bei RMS und PPMS führten die anschließenden Phase-3-Studien, die alle ihre primären klinisch definierten Endpunkte erreichten: die beiden identisch designten Studien OPERA I und II zu Ocrelizumab vs. Interferon- $\beta_{1 \mathrm{a}}$ (intramuskulär) bei RMS [25] sowie die Studie ORATORIO zu Ocrelizumab vs. Placebo bei früher PPMS [26] definiert über Alter (18 bis 55 Jahre) und Erkrankungsdauer ( $<15$ Jahre bei EDSS $>5,0$ bzw. $<10$ Jahre bei EDSS <5,0). 
Tab. 2 Phase-2- und -3-Studien von Rituximab zur Behandlung von Multiple-Sklerose-Patienten

\begin{tabular}{|c|c|c|}
\hline Studie & $\begin{array}{l}\text { Primärer Endpunkt } \\
\text { Ergebnis }\end{array}$ & $\begin{array}{l}\text { Sekundärer Endpunkt } \\
\text { Ergebnis }\end{array}$ \\
\hline $\begin{array}{l}\text { Phase-2-RRMS } \\
\text { Hauser et al. [21] } \\
\text { (HERMES) } \\
n=104 \text { Patienten }\end{array}$ & $\begin{array}{l}\text { Summe der Anzahl der gadoliniumpo- } \\
\text { sitiven T1-Läsionen in Serien-MRTs des } \\
\text { Gehirns in den Wochen 12, 16, 20, } 24 \\
\rightarrow \text { Rituximab Placebo überlegen }\end{array}$ & $\begin{array}{l}\text { Anteil der Patienten mit Schüben } \\
\text { Auf das Jahr umgerechnete Schubrate } \\
\text { Absolute Anzahl von neuen gadoliniumpositiven T1-Läsionen in Serien-MRTs } \\
\text { des Gehirns in den Wochen 12, 16, 20, } 24 \text { und } \\
\text { Änderung des T2-Läsionsvolumens im Vergleich zum Ausgangswert } \\
\rightarrow \text { Rituximab Placebo überlegen }\end{array}$ \\
\hline $\begin{array}{l}\text { Phase-2/3-PPMS } \\
\text { Hawker et al. [22] } \\
\text { (OLYMPUS) } \\
n=439 \text { Patienten }\end{array}$ & $\begin{array}{l}\text { Zeit bis zum Einsetzen von CDP } \\
\text { Prozentsatz der Patienten mit CDP } \\
\rightarrow \text { Kein Hinweis für einen signifikanten } \\
\text { Unterschied }\end{array}$ & $\begin{array}{l}\text { Änderung des absoluten T2-Läsionsvolumens in Woche } 96 \text { im Vergleich zum } \\
\text { Ausgangswert } \\
\text { Änderung des Hirnvolumens in Woche } 96 \text { im Vergleich zum Ausgangswert } \\
\rightarrow \text { Patienten, die Rituximab erhalten haben, hatten eine signifikant geringere Zu- } \\
\text { nahme an T2-Läsionsvolumen }\end{array}$ \\
\hline
\end{tabular}

Tab. 3 Phase-2-und-3-Studien von Ocrelizumab zur Behandlung von Multiple-Sklerose-Patienten

\begin{tabular}{|c|c|c|}
\hline Studie & $\begin{array}{l}\text { Primärer Endpunkt } \\
\text { Ergebnis }\end{array}$ & $\begin{array}{l}\text { Sekundärer Endpunkt } \\
\text { Ergebnis }\end{array}$ \\
\hline $\begin{array}{l}\text { Phase-2-RRMS } \\
\text { Kappos et al. } \\
{[24]}\end{array}$ & $\begin{array}{l}\text { Anzahl der gado- } \\
\text { liniumpositiven } \\
\text { T1-Läsionen zwischen } \\
\text { Woche } 12 \text { und } 24 \\
\rightarrow \text { Ocrelizumab Place- } \\
\text { bo überlegen }\end{array}$ & $\begin{array}{l}\text { Auf das Jahr umgerechnete Schubrate } \\
\text { Prozentsatz der schubfreien Patienten } \\
\text { Änderung des absoluten T2-Läsionsvolumens } \\
\text { Anzahl der neuen gadoliniumpositiven T1-Läsionen zwischen Woche } 4 \text { und } 24 \\
\text { Anzahl der gadoliniumpositiven T1-Läsionen zwischen Woche } 4 \text { und } 24 \\
\rightarrow \text { Ocrelizumab Placebo in allen Punkten überlegen außer Prozentsatz der schubfreien Patienten und Änderung } \\
\text { des absoluten T2-Läsionsvolumens }\end{array}$ \\
\hline $\begin{array}{l}\text { Phase-3-RMS } \\
\text { Hauser et al. } \\
\text { [25] } \\
\text { (OPERA I } \\
\text { und II) }\end{array}$ & $\begin{array}{l}\text { Auf das Jahr umge- } \\
\text { rechnete Schubrate } \\
\rightarrow \text { Ocrelizumab IFN- } \beta_{1 a} \\
\text { überlegen }\end{array}$ & $\begin{array}{l}\text { Zeit bis zum Einsetzen von CDP } \\
\text { Anzahl der gadoliniumpositiven T1-Läsionen } \\
\text { Anzahl der neuen und/oder vergrößerten T2-Läsionen } \\
\text { Prozentsatz der Patienten mit CDI } \\
\text { Anzahl der T1-Läsionen } \\
\text { Änderung des MSFC im Vergleich zum Ausgangswert } \\
\text { Prozentsatzänderung des Hirnvolumens } \\
\text { Änderung des Short Form Health Survey-36 (SF-36) Physical Component Summary (PCS) im Vergleich zum } \\
\text { Ausgangswert } \\
\text { Prozentsatz der Patienten mit NEDA } \\
\rightarrow \text { Ocrelizumab überlegen in allen sekundären Endpunkten außer MSFC und SF-36 in OPERA I und überlegen in } \\
\text { allen sekundären Endpunkten außer CDI und Prozentsatzänderung des Hirnvolumens in OPERA II }\end{array}$ \\
\hline $\begin{array}{l}\text { Phase-3-PPMS } \\
\text { Montalban } \\
\text { et al. [26] } \\
\text { (ORATORIO) }\end{array}$ & $\begin{array}{l}\text { Zeit bis zum Einsetzen } \\
\text { von anhaltender } \\
\text { CDP für mindestens } \\
12 \text { Wochen } \\
\rightarrow \text { Ocrelizumab Place- } \\
\text { bo überlegen }\end{array}$ & $\begin{array}{l}\text { Zeit bis zum Einsetzen von anhaltender CDP für mindestens } 24 \text { Wochen } \\
\text { Prozentsatzänderung des T25-FW im Vergleich zum Ausgangswert } \\
\text { Prozentsatzänderung des absoluten T2-Läsionsvolumens im Vergleich zum Ausgangswert } \\
\text { Prozentsatzänderung des Hirnvolumens } \\
\text { Änderung im Physical Component Summary Score (PCS) und SF-36 Health Survey } \\
\text { Prozentsatz der Patienten mit mindestens einem unerwünschten Ereignis } \\
\rightarrow \text { Ocrelizumab überlegen in Bezug auf Zeit bis zum Einsetzen von anhaltender CDP für mindestens } 24 \text { Wo- } \\
\text { chen, Prozentsatzänderung des T25-FW im Vergleich zum Ausgangswert; Prozentsatzänderung des absoluten } \\
\text { T2-Läsionsvolumens im Vergleich zum Ausgangswert, Prozentsatzänderung des Hirnvolumens }\end{array}$ \\
\hline
\end{tabular}

T25FW Timed 25-Foot Walk, MSFC Multiple Sclerosis Functional Composite, NEDA "no evidence of disease activity" (kein Anhalt für Krankheitsaktivität), $C D P$ "confirmed disability progression" (bestätigte Krankheitsprogression), CDI "confirmed disability improvement" (bestätigte Verbesserung des Behinderungsgrads), IFN Interferon

Tab. 4 Indikationen für Ocrelizumab gemäß EMA [30]

Ocrelizumab ist angezeigt zur Behandlung erwachsener Patienten mit schubförmiger Multipler Sklerose (RMS) mit aktiver Erkrankung, definiert durch klinischen Befund oder Bildgebung

Ocrelizumab ist angezeigt zur Behandlung erwachsener Patienten mit früher primär progredienter Multipler Sklerose (PPMS), charakterisiert anhand der Krankheitsdauer und dem Grad der Behinderung sowie mit Bildgebungsmerkmalen, die typisch für eine Entzündungsaktivität sind
In den OPERA-Zwillingsstudien bei RMS reduzierte Ocrelizumab die jährliche Schubrate gegenüber IFN- $\beta_{1 \mathrm{a}}$ um $46 \%$ bzw. $47 \%$ (jeweils $p<0,0001$ ). $\mathrm{Zu}$ dem wurden alle sekundären Endpunkte erreicht, darunter die Reduktion der Behinderungsprogression bzw. die Besserung der Behinderung (jeweils mit Bestätigung nach 12 und 24 Wochen) und ma- 


\begin{tabular}{|c|c|c|c|}
\hline \multirow{2}{*}{$\begin{array}{l}\text { Initialdosis }(600 \mathrm{mg}) \\
\text { aufgeteilt auf } \\
2 \text { Infusionen }\end{array}$} & Infusion 1 & $\begin{array}{l}300 \mathrm{mg} \text { in } \\
250 \mathrm{ml}\end{array}$ & \multirow{2}{*}{$\begin{array}{l}\text { Infusionseinleitung mit einer Geschwindigkeit von } 30 \mathrm{ml} / \mathrm{h} \text { über } 30 \mathrm{~min} \\
\text { Die Geschwindigkeit kann in Schritten von } 30 \mathrm{ml} / \mathrm{h} \text { alle } 30 \mathrm{~min} \text { bis auf einen Höchstwert } \\
\text { von } 180 \mathrm{ml} / \mathrm{h} \text { gesteigert werden } \\
\text { Die Infusionsdauer sollte jeweils ca. } 2,5 \text { h betragen }\end{array}$} \\
\hline & $\begin{array}{l}\text { Infusion } 2 \text { ( } 2 \text { Wo- } \\
\text { chen später) }\end{array}$ & $\begin{array}{l}300 \mathrm{mg} \text { in } \\
250 \mathrm{ml}\end{array}$ & \\
\hline $\begin{array}{l}\text { Folgedosen }(600 \mathrm{mg}) \\
\text { einmal alle } 6 \text { Monate }\end{array}$ & Einmalinfusion & $\begin{array}{l}600 \mathrm{mg} \text { in } \\
500 \mathrm{ml}\end{array}$ & $\begin{array}{l}\text { Infusionseinleitung mit einer Geschwindigkeit von } 40 \mathrm{ml} / \mathrm{h} \text { über } 30 \mathrm{~min} \\
\text { Die Geschwindigkeit kann in Schritten von } 40 \mathrm{ml} / \mathrm{h} \text { alle } 30 \mathrm{~min} \text { bis auf einen Höchstwert } \\
\text { von } 200 \mathrm{ml} / \mathrm{h} \text { gesteigert werden } \\
\text { Die Infusionsdauer sollte jeweils ca. 3,5 h betragen }\end{array}$ \\
\hline
\end{tabular}

gnetresonanztomographische Wirksamkeitskriterien, wobei die Reduktion der prozentualen Veränderung des Hirnvolumens nur in OPERA I statistisch signifikant war. Den Status NEDA über 2 Jahre erreichten in beiden Studien $48 \%$ der Patienten in der Ocrelizumab-Gruppe gegenüber $29 \%$ bzw. $25 \%$ unter der aktiven Vergleichstherapie.

Eine jüngst veröffentlichte Post-hocAnalyse belegte eine bestätigte Verbesserung der Armfunktion, erfasst in 12wöchigen Abständen mit dem 9 Hole Peg Test (9HPT). In der Intention-to-treatAnalyse war auch der Anteil von Patienten mit bestätigter Verschlechterung im 9HPT geringer in der Ocrelizumabbehandelten Gruppe [27].

In einer kürzlich veröffentlichen Analyse der Krankheitsprogression in den OPERA-Studien, zeigt sich, dass in der gesamten RMS-Population der größte Anteil der erworben Behinderung schubunabhängig erfolgt [28].

In der 120-wöchigen PPMS-Studie ORATORIO erreichte Ocrelizumab sowohl den primären Endpunkt (Reduktion des Risikos einer nach 12 Wochen bestätigten Behinderungsprogression) als auch die sekundären Endpunkte. Der Anteil der Patienten mit bestätigter Krankheitsprogression im EDSS-Score nach 12 Wochen war gegenüber Placebo um $24 \%$ reduziert. Subanalysen der Handfunktion (9HPT) und Gehfähigkeit (T25FW) bestätigten die Überlegenheit von Ocrelizumab in diesen Teilbereichen der motorischen Funktion [26].

Es ist zu erwähnen, dass in der PPMSStudie nur Patienten eingeschlossen wurden, die eine relativ kurze Erkrankungsdauer - definiert über Alter (18 bis 55 Jahre) und Erkrankungsdauer (Symptomdauer $<15$ Jahre bei Patienten mit einem
EDSS-Wert von $>5,0$ oder $<10$ Jahre bei Patienten mit einem EDSS von $<5,0$ zum Zeitpunkt des Screenings) - hatten.

Das Volumen von T2-Hirnläsionen nahm in der Ocrelizumab-Gruppe um $3,4 \% \mathrm{ab}$, während es unter Placebo um 7,4\% anstieg. Die Anzahl neuer T2-Läsionen war unter Ocrelizumab gegenüber Placebo um 92\% reduziert [26]. Auch die Abnahme des Gehirnvolumens war in der Gruppe mit aktiver Therapie signifikant vermindert. Subgruppenanalysen zufolge war das Ansprechen auf Ocrelizumab nicht von der Präsenz gadoliniumaufnehmender Läsionen zu Beginn der Studie abhängig [26].

Bei Neuromyelitis-optica-Spektrumerkrankungen (NMOSD), einer Gruppe schubförmig verlaufender chronischentzündlicher ZNS-Erkrankungen mit pathognomonischer Astrozytopathie, konnte gezeigt werden, dass eine B-ZellRepopulation mit einem Anstieg der Schubrate assoziiert ist [29]. Inwiefern sich dieser Zusammenhang auf die RMS übertragen lässt, ist bislang allerdings unklar.

In den Zulassungsstudien kam es bei $20,7 \%$ der RMS-Patienten und bei 26,3\% der PPMS-Patienten zu einem Abfall der absoluten Lymphozyten unterhalb des unteren Normalwertes [30]. Die Mehrheit der Patienten entwickelte eine Grad-1- oder -2-Lymphopenie, die Rate der Grad-3-Lymphopenien lag bei $1 \%$ und bereits nach 2 Wochen ließen sich keine CD19-positiven Zellen mehr im Blut nachweisen [22, 26, 30]. Nach 2,5 Jahren (Median 72 Wochen) Ocrelizumab-Therapiepause hat sich bei $90 \%$ der Patienten die Lymphozytenpopulation erholt [30]. Im Vergleich dazu hat sich die Lymphozytenpopulation in der Rituximab-Phase-2/3-Studie (OLYMPUS) nach 48 Wochen bei $35 \%$ der Patienten erholt [22]. In den Folgestudien nach Marktzulassung am 12.01.2018 ([30]; Indikationen siehe Tab. 4; Anwendungsschema siehe $\bullet$ Tab. 5) konnte der Nutzen von Ocrelizumab weiter bestätigt werden: $66,4 \%$ der RMS-Patienten unter Ocrelizumab und 24,3\% der Patienten unter Interferon- $\beta_{1 \mathrm{a}}$ zeigten keinen Hinweis für klinische oder radiologische Krankheitsaktivität („no evidence of disease activity“, NEDA; [31]). Da direkte Vergleichsstudien von Ocrelizumab gegen andere MS-Therapien fehlen, wurde eine Metaanalyse durchgeführt, die zeigte, dass der Nutzen einer OcrelizumabTherapie insbesondere bei Patienten mit hochaktiver RMS gegeben ist [32]. Ferner lieferten zahlreiche retrospektive Analysen und eine Subgruppenanalyse Hinweise dafür, dass Rituximab sowohl effektiv bei aggressiver RMS bzw. progressiver MS sein kann [33-39] als auch den MS-Therapien der 1. Generation (i.e. Interferon- $\beta$ und Glatirameracetat) überlegen ist [40, 41]. Ob Rituximab allerdings eine gleichwertige Alternative zu Ocrelizumab darstellt, bleibt in Abwesenheit einer Kopf-an-Kopf-PhaseIII-Studie Gegenstand von Diskussionen [42-45]. Direkte Vergleichsstudien zwischen Rituximab und anderen Therapieoptionen wären sinnvoll, um diese Wissenslücken zu schließen [46].

Um das Ansprechen der PPMS-Patienten auf eine Immuntherapie besser charakterisieren zu können, wird seit kurzem der Summenparameter mit dem Akronym NEPAD - „no evidence of progression or active disease " - verwendet. In der ORATORIO-Studie erhöhte Ocrelizumab den Anteil der PPMS-Patienten mit NEPAD nach 120 Wochen im Vergleich zu Placebo um das Drei- 


\begin{tabular}{llll}
\hline $\begin{array}{l}\text { Tab. } 6 \\
\text { kungen unter Ocrelizumab in den Pha- }\end{array}$ & \multicolumn{1}{l}{$\begin{array}{l}\text { Schwerwiegende Nebenwir- } \\
\text { se-3-Zulassungsstudien }\end{array}$} \\
\hline Studie & Anzahl & $\begin{array}{l}\text { Davon Infek- } \\
\text { tionen }\end{array}$ \\
\hline OPERA I & $28(6,9 \%)$ & $5(1,2 \%)$ \\
\hline OPERA II & $29(7,0 \%)$ & $6(1,4 \%)$ \\
\hline ORATORIO & $99(20,4 \%)$ & $30(6,2 \%)$
\end{tabular}

fache [47]. Eine Analyse der gepoolten Daten aus den Phase-2- und -3-Studien legt nahe, dass Ocrelizumab die MRTLäsionsaktivität innerhalb von 4 Wochen und klinische Krankheitsaktivität innerhalb von 8 Wochen effektiv unterdrückt [48]. Eine MR-SpektroskopieStudie mit sequenzieller Messung über 96 Wochen eines Markers des „neuronal-myelin coupling" (NAA, tCr, tCho und NAA/tCr) zeigt, dass Ocrelizumab das Ausmaß einer zerebralen Gliose im Vergleich zu Interferon- $\beta$ reduziert [49]. Die klinische Progression scheint bei PPMS-Patienten mit chronischer Läsionsaktivität in der weißen Substanz assoziiert zu sein [50].

\section{Ocrelizumab: Nebenwirkungen}

\section{Akute Infusionsreaktionen}

Als relevante Nebenwirkungen traten unter Ocrelizumab gegenüber Placebo häufiger akute Infusionsreaktionen und Infektionen auf. Die Häufigkeiten der schwerwiegenden Nebenwirkungen in den Zulassungsstudien sind in - Tab. 6 zusammengefasst. Weitere laufend aktualisierte Daten - insbesondere zu Infektionen und Neoplasien - werden regelmäßig auf Kongressen vorgestellt und ergaben bislang keine neuen Sicherheitsaspekte [51].

Eine retrospektive Studie konnte zeigen, dass das Auftreten von infusionsassoziierten Reaktionen durch die zusätzliche Gabe von Histaminantagonisten und oraler Flüssigkeitszufuhr deutlich reduziert werden kann [52].

\section{Malignome}

Im klinischen Studienprogramm wurde bei Patienten, die mit Ocrelizumab behandelt wurden, eine verglichen mit den Kontrollgruppen höhere Anzahl maligner Erkrankungen (einschließlich Mammakarzinom) beobachtet [53, 54].

In der 2:1 randomisierten Zulassungsstudie zur PPMS wurden unter Ocrelizumab (486 Patienten) in der placebokontrollierten Phase 11 Neoplasien verzeichnet, (Mammakarzinom 4, Basalzellkarzinom 3, endometrioides Adenokarzinom 1, anaplastisches großzelliges Lymphom 1, fibröses Histiozytom 1, Pankreaskarzinom 1), während in der Placebogruppe (239 Patienten) in der kontrollierte Studienphase 2 Neoplasien auftraten (Basalzellkarzinom 1, zervikales Adenokarzinom in situ 1; [26]).

Bei den RMS-Patienten unter Ocrelizumab traten in den 2-jährigen kontrollierten Phasen der OPERA-Studien insgesamt 4 maligne Erkrankungen auf (Mammakarzinom 2; Nierenzellkarzinom 1, malignes Melanom 1) und in der mit IFN- $\beta_{1 a}$ behandelten Gruppe 2 (Mantelzell-Lymphom 1 und pulmonales Plattenepithelkarzinom 1; [25]).

Jährlich aktualisierte Analysen (aktueller Stand Januar 2019) zur Inzidenzrate von malignen Erkrankungen (ohne nichtmelanotische Hautmalignome) bei den weiter beobachteten Patienten des klinischen Studienprogramms zu Ocrelizumab zeigen, dass die alters- und geschlechtsstandardisierten Raten pro 100 Patientenjahre in der exponierten Population über die Zeit stabil blieben und keinen zeitabhängigen Expositionseffekt zeigen. Des Weiteren ergaben Vergleiche der standardisierten Inzidenzraten für alle maligne Erkrankungen und für Mammakarzinome mit der US-amerikanischen SEER-Datenbank (Allgemeinbevölkerung) und dem dänischen MS-Register, dass die beobachteten Inzidenzraten im gesamten bisherigen Beobachtungszeitraum innerhalb der epidemiologischen Referenzbereiche lagen [55].

\section{Infektionen}

Fallberichte weisen auf das Risiko einer Hepatitisreaktivierung unter CD20-Depletion hin [56, 57], daher ist eine Risikostratifizierung vor Therapiebeginn sinnvoll [58]. Ferner wurden als Risiken eine Late-onset-Neutropenie $[59,60]$ und das Auftreten tumefaktiver, demyelini- sierender Läsionen beschrieben [61]. Es sind wenige Fälle einer „,carry-over“ progressiven multifokalen Leukenzephalopathie (PML) bekannt geworden. Diese traten nach vorangegangener Therapie mit anderen Immunmodulatoren mit bekannt erhöhtem PML-Risiko auf (7 Fälle Stand Ende 2019) [62, 63]. Aktuell ist eine nichtinterventionelle Studie geplant, die das Langzeitrisikoprofil von Ocrelizumab besser erfassen soll [64]. Die Ergebnisse dieser Studie in Deutschland flieBen auch in globale Sicherheitsregister ein [65].

Dieser Kontext ist ähnlich wie bei den Fällen einer PML in Assoziation mit dem Vorläuferpräparat Rituximab in anderen Nicht-MS-Indikationen, wie z. B. rheumatoider Arthritis [66]. Die Auswertung eines Rituximab-Therapieregisters ergab keine neuen Aspekte hinsichtlich des Nebenwirkungsprofils von CD20-Depletion [67]. Es gibt Hinweise dafür, dass ein sekundärer Immunglobulinmangel das Auftreten schwerer Infektionen begünstigen kann [68]. In einem Review über das Risiko einer Hypogammaglobulinämie bzw. Infektion unter Rituximab konnten jedoch keine klaren Risikofaktoren herausgearbeitet werden [69]. Wie unter Rituximab sollte unter Ocrelizumab regelmäßig der IgGSpiegel kontrolliert werden [70]. Dies ist insbesondere relevant, da die Infektionsrate unter CD20-Depletion bei MSPatienten am höchsten zu sein scheint [71].

Bei einer 78 Jahre alten Patientin, mit niedrigen $\mathrm{CD}^{+}$- und $\mathrm{CD} 8^{+}-\mathrm{Lym}-$ phozytenzahlen vor Therapiebeginn und vermuteter Immunseneszenz wurde eine PML unter Ocrelizumab ohne Vorexposition gegenüber anderen immunologischen Therapien gemeldet [72].

Bezüglich anderer infektiöser Komplikationen wurden einzelne Fallberichte von Patienten publiziert, die unter einer Ocrelizumab-Behandlung eine Herpes-simplex-Typ-2-Enzephalitis [73], eine Parvovirus-B19-Infektion [74] und in 2 Fällen eine Meningitis entwickelten. In einem Fall verlief die Meningitis aseptisch, bei der anderen konnte eine vermutete Borreliengenese nicht verifiziert werden [75]. Ein Fallbericht legt nahe, dass Ocrelizumab zwar B-Zellen deple- 
tiert, jedoch nicht die T-Zell-Immunantwort auf Varizella Zoster beeinflusst [76].

Kürzlich wurde unter Ocrelizumab das Auftreten einer Endokarditis berichtet [77].

Die Therapie mit Ocrelizumab ist wahrscheinlich nicht mit einem erhöhten Risiko einer Tuberkuloseinfektion assoziiert [78].

Es ist zu beachten, dass es bei RMS-Patienten unter Ocrelizumab im Vergleich $\mathrm{zu}$ Interferon- $\beta_{1 \mathrm{a}}$ mehr Infektionen mit Varizella-Zoster-Viren ( $n=17$ vs. 8 [25]) auftraten und bei PPMS-Patienten unter Ocrelizumab im Vergleich zu Placebo mehr Episoden mit oralem Herpes simplex (2,3\% vs. $0,4 \%$; [25]). In der Zusammenschau sind regelmäßige Verlaufskontrollen bei MS-Patienten unter CD20-depletierenden Therapien sinnvoll [79].

Obwohl sowohl eine retrospektive Analyse von Patienten mit neuroimmunologischen Erkrankungen unter 7-jähriger Rituximab-Therapie [80] als auch eine Metaanalyse von Patienten mit rheumatoider Arthritis [81] ein günstiges Sicherheitsprofil bestätigen konnten, ist der Einfluss einer LangzeitB-Zell-Depletion auf Malignom- und Infektionsrisiken nicht vollständig charakterisiert [82, 83]. Für Ocrelizumab liegen aktuell aus klinischen Studien Daten von Patienten mit bis zu 6 Jahren Exposition vor, mit einer Gesamtexposition von über 14.000 Patientenjahren (Stand Mai 2019; [55]).

\section{Schwangerschaften unter CD20- gerichteter Therapie}

Es zeigten sich keine klaren Sicherheitssignale (i.e. Spontanaborte oder kindliche Fehlbildungen) bei Schwangeren, die in den ersten 6 Schwangerschaftsmonaten eine CD20-Depletion mittels Rituximab erfahren haben [84]. Die Auswertung der bisher dokumentierten Schwangerschaften mit Ocrelizumab-Exposition ergab keine Auffälligkeiten [85]. Weitere Daten werden im Ocrelizumab-Schwangerschaftsregister erhoben [86].

Die Datenlage bezüglich intrathekaler Applikation von CD20-depletierenden monoklonalen Antikörpern ist gering [87]. Ferner ist hervorzuheben, dass es bei RMS-Patienten unter Ocrelizumab im Vergleich zu Interferon- $\beta_{\text {1a }} \mathrm{zu}$ mehr Varizella-Zoster-Infektionen (17 vs. 8 [25]) und bei PPMS-Patienten unter Ocrelizumab im Vergleich zu Placebo zu mehr oralen Herpesinfektionen (2,3\% vs. $0,4 \%$; [26]) gekommen ist.

\section{Pathomechanistische Aspekte der Rolle von B-Zellen in der MS}

Die rasch einsetzenden tiefgreifenden Effekte einer CD20-B-Zell-gerichteten Therapie haben $\mathrm{zu}$ einer Neubewertung der humoralen Immunantwort bei MS geführt. Nach ursprünglicher Vorstellung würde eine B-Zell-Depletion vermutlich wesentlich über eine Verminderung der Produktion von Autoantikörpern wirken.

Die Wirkungsweise von CD20-Depletion bei MS und den autoimmunen Tiermodellen ist allerdings bisher nicht vollständig verstanden [88]. Die aktuelle Datenlage hinsichtlich der B-ZellRolle bei MS wurde rezent mehrfach zusammengefasst [7, 14, 89-92] und die Interaktion von B- und T-Zellen diskutiert [93]. Die Effektivität der B-ZellDepletion bei MS unterstützt die Hypothese, dass mit Epstein-Barr-Viren latent infizierte B-Zellen eine wichtige Rolle bei der Pathogenese der MS spielen könnten [94, 95]. Aus tierexperimentellen Studien gibt es Hinweise, dass eine CD20-Depletion die Aktivierung von Mikrogliazellen und die Rekrutierung von T-Lymphozyten reduziert [96]. Die pathogene CD40-vermittelte NF- $\kappa \mathrm{B}$-Aktivierung in B-Zellen ist bei MS-Patienten verstärkt [97]. Zusätzlich werden B-Zell Aggregate in lymphfollikelähnlichen Strukturen im Subarachnoidalraum, insbesondere bei Patienten mit sekundär chronisch-progredienter Verlaufsform, als erkrankungsrelevant diskutiert [98, 99]. Eine tierexperimentelle Studie konnte diesbezüglich zeigen, dass eine intrathekale Gabe von AntiCD20-Antikörpern zu einer relevanten Depletion von B-Zellen in etablierten ZNS-Läsionen führt [100]. Des Weiteren gibt es Hinweise dafür, dass es bei MSPatienten einen Transit zwischen dem ZNS und der Peripherie von insbesondere immunaktiven B-Zellen gibt, die einen Immunglobulinklassenwechsel erfahren haben [101], und dass B-Zellen von MS-Patienten vermehrt Antigene präsentieren [102]. Diese Immunzellen müssen dabei mittels komplexer, mehrschrittiger Kaskaden Immunbarrieren überwinden [103], um dort klonal zu expandieren [104] und spezifische Immunglobuline zu produzieren [105] und Lymphangiogenese zu fördern [106]. Die Reifung der ZNS-ständigen B-Zellen bei MS-Patienten erfolgt nach aktuellem Wissenstand in den drainierenden zervikalen Lymphknoten [107]. B-Zellen von RRMS-Patienten sind in der Lage, komplement- und immunglobulinunabhängige Faktoren zu produzieren, die in vitro toxisch für Neurone und Oligodendrozyten sind [108]. Bei Patienten mit Myelitis als klinisch isoliertem Syndrom, die sich somit im Anfangsstadium einer möglichen MS befinden, konnte sowohl eine expandierte und mutierte Plasmablastensubgruppe [109] als auch eine bestimmte Verteilung von Interleukin6/-10-produzierenden B-Lymphozyten differenziert werden [110], was im Einklang mit dem aktuellen Verständnis über die Rolle der Zytokine bei autoimmunen Erkrankungen steht [111]. Somit scheint es, dass B-Zellen sowohl zu Beginn als auch bei der Aufrechterhaltung der MS-Erkrankung eine wichtige Rolle spielen [112]. Wichtig dabei scheint die Regulierung des „Macrophage-migration-inhibitory-factor"(MIF)-Signalwegs zu sein, da ein supprimiertes CD74 und ein hochreguliertes CXCR4 mit einer frühen MS-Diagnose assoziiert sind [113]. Ferner wird diskutiert, dass nicht alle B-Lymphozyten pathophysiologisch relevant sind, sondern insbesondere eine bestimmte Subgruppe, und zwar „Granulocyte-macrophage-colony-stimulatingfactor"(GM-CSF)-exprimierende humane B-Gedächtnis-Zellen [114], bzw. verschiedene B-Lymphozyten-Subgruppen im Liquor entscheidend sind für den Erkrankungsphänotyp [115]. Basierend auf den Erkenntnissen über die phasenabhängige Oberflächenexpression von Differenzierungsantigenen in der B-ZellReifung und der Diskussion einer aktuellen Phase-2/3-Studie von Inebilizumab, ein gegen CD19 gerichteter monoklonaler Antikörper, bei NMOSD [116] 
muss zwischen CD20- und CD19-Depletion unterschieden werden (• Abb. 1): CD20 wird nicht auf der Oberfläche von Plasmazellen exprimiert, wohingegen CD19 auf der Mehrheit von Plasmazellen in sekundären lymphatischen Organen (z. B. Milz, Tonsillen), auf allen Plasmazellen im Blut und bei mehr als $50 \%$ der Plasmazellen im Knochenmark nachgewiesen werden kann $[117,118]$. Zusätzlich muss beachtet werden, dass CD19 nur von Plasmazellen, CD20 jedoch auch von einer Untergruppe CDpositiver T-Zellen exprimiert wird [119]. In der Zusammenschau sind B-Zellen allerdings nicht alleinig für die Entstehung und Aufrechterhaltung der MS verantwortlich: Es gibt Hinweise dafür, dass (Gedächtnis-)B-Zellen autoreaktive, autoproliferative [120], proinflammatorische T-Zellen (u.a. $\mathrm{T}_{\mathrm{H}} 17-$ Zellen) induzieren, die wiederum eine entscheidende Rolle in den Entzündungskaskaden im ZNS spielen [121-123], und dass „polymorphonuclear myeloid-derived suppressor cells“ (PMN-MDSCs) selektiv die Akkumulierung von B-Zellen im ZNS kontrollieren [124]. Nichtsdestotrotz war es bis heute nicht möglich, ein bestimmtes Zielantigen dieser Immunzellen zu identifizieren [125]. Zusätzlich ist bislang unklar, welche Rolle die kleine Subgruppe der CD20-positiven T-Zellen bei der MS spielt [126]. So zeigte eine Phase-2a-Studie mit dem CD20depletierenden Antikörper Ublituximab eine Veränderung des T-Zell-Profils bei MS-Patienten unter Therapie [127].

\section{Ocrelizumab: Indikationen, praktische Aspekte und Therapiehinweise}

Die Indikationen von Ocrelizumab sind in Tab. 4, das Anwendungsschema in Tab. 5 und der detaillierte Infusionsablauf im Handbuch Ocrelizumab des Kompetenznetzes Multiple Sklerose [128] dargestellt: Hinsichtlich der Indikationen ist zu beachten, dass Ocrelizumab auch für die Behandlung einer sekundär chronisch-progredienten MS zugelassen ist, sofern weiterhin aufgelagerte Schübe vorliegen. Diese relativ breite Zulassung liegt ebenfalls für die hochaktive Therapie mit Cladribin, jedoch formal nicht für Fingolimod, Natalizumab und Alemtuzumab vor.

Je nach Vortherapie sollte vor Ocrelizumab-Therapiebeginn ein Sicherheitsabstand zur Vortherapie eingehalten werden. Nach Interferon- $\beta$, Dimethylfumarat oder Glatirameracetat sollten mögliche Effekte auf Laborwerte abgeklungen sein, Teriflunomid sollte ausgewaschen und nicht mehr im Blut nachweisbar sein, bei Fingolimod beträgt der Sicherheitsabstand mindestens 4 Wochen, bei Natalizumab 6 bis 8 Wochen, bei Cladribin 6 Monate und bei Alemtuzumab 6 bis 12 Monate. Laborchemische Untersuchungen vor Ocrelizumab-Infusion sind erforderlich. Wichtig ist, dass in Einzelfällen ggf. von oben genannten Sicherheitsabständen abgewichen werden muss, basierend auf einer individuellen Risiko-Nutzen-Bewertung. Es wird ein Differenzialblutbild, ein IgGSpiegel im Serum, CRP, Urinstatus und ggf. ein Schwangerschaftstest empfohlen. Infektiologisch sollte vor OcrelizumabTherapiebeginn eine Hepatitis-B/C-, HIV-, VZV-Serologie sowie bez. Tuberkulose ein Interferon- $\gamma$-Freisetzungstest (z.B. Quantiferon) erfolgen. Patienten mit ausgeheilter, nicht mehr aktiver Hepatitis B können ggf. Ocrelizumab erhalten, jedoch ist analog zu dem Vorgehen bei Rituximab eine Vorstellung in einem Leberzentrum zur Diskussion einer prophylaktischen Therapie mit Tenofovir und engmaschige Kontrollen der HBV-DNA im Blut sinnvoll [129-131]. Alle 6 Monate sollte unter Therapie das Differenzialblutbild und ein IgGSerumspiegel kontrolliert werden. Ocrelizumab kann zu einem erniedrigten IgG-Spiegel führen [132]. Bei erhöhter Infektanfälligkeit und erniedrigtem IgG-Serumspiegel kann eine intravenöse IgG-Substitution nach internistischer Maßgabe erfolgen. Immunphänotypisierungen vor und während der Therapie sind nicht obligat, sondern fakultativ.

Vor Ocrelizumab-Infusion sollte eine Vortherapie mit $100 \mathrm{mg}$ Methylprednisolon intravenös und ein Antihistaminikum verabreicht werden, um eine mögliche Infusionsreaktion $\mathrm{zu}$ minimieren. Das medizinische Personal, das Ocrelizumab verabreicht, sollte für die Behandlung schwerer anaphylaktischer Re- aktionen geschult sein, ferner ist ein uneingeschränkter Zugang zu intensivmedizinscher Versorgung in der eigenen oder nächstliegenden Einrichtung sinnvoll. Patienten sollten nach OcrelizumabInfusion für mindestens $1 \mathrm{~h}$ nachbeobachtet werden. Eine klinisch-neurologische Behandlungskontrolle ist nach dem ersten Behandlungsmonat und im Verlauf einmal im Quartal sinnvoll. Ferner sollte nach einem Jahr Therapie eine kritische Prüfung der Therapieindikation nicht nur hinsichtlich des Effekts auf den Krankheitsverlauf, sondern auch hinsichtlich Nebenwirkungen und paraklinischer Befunde erfolgen. Eine MRT des Schädels ist 3 Monate („baseline“ nach Einsetzen der therapeutischen Wirkung) nach Therapiebeginn und im Verlauf einmal jährlich sinnvoll. Auf eine Kontrastmittelgabe kann dabei verzichtet werden [133]. Sollte es notwendig sein, die Ocrelizumab-Therapie umzustellen, ist eine 6- bis 12-monatige Therapiepause sinnvoll, ferner sollte eine Zytopenie möglichst abgeklungen sein.

Sollte es bei einer schubförmigen MS zu Krankheitsaktivität unter Ocrelizumab kommen, kann eine Umstellung auf eine andere hochaktive Therapie sinnvoll sein. Der Einsatz von Ocrelizumab ist bei PPMS-Patienten im frühen Krankheitsstadium mit entzündlicher Aktivität sinnvoll [134]. Da Ocrelizumab das einzige zur Behandlung der primär chronischprogredienten MS zugelassene Medikament ist, kann bei PPMS-Progression unter Ocrelizumab mangels zugelassener Therapiealternativen keine Empfehlung zur Umstellung erfolgen, sondern die Therapie wird in den meisten Fällen fortgeführt werden. Patienten, die bereits vor Zulassung von Ocrelizumab auf Rituximab eingestellt sind und keine Krankheitsaktivität und Nebenwirkungen zeigen, können aus medizinischer Sicht die Rituximab-Therapie fortsetzen. Da dies „off label“ ist, empfiehlt sich die vorherige Einholung einer Kostenübernahmeerklärung der Krankenversicherung.

Hinsichtlich viraler Epidemien (wie z.B. aktuell SARS-CoV-2/COVID19) besteht laut einer Stellungnahme der Deutschen Multiple Sklerose Gesellschaft (DMSG) ein erhöhtes Risiko, unter Ocrelizumab zu erkranken [135]. 
Da bei Ocrelizumab das Infektionsrisiko unmittelbar nach Infusion am größten ist, kann eine Streckung des Intervalls individuell diskutiert werden [136] und die Indikation zur Ersteinstellung ist kritisch zu stellen. Laut Kompetenznetz Multiple Sklerose (KKNMS) besteht bei Patienten unter Ocrelizumab insbesondere in den ersten Wochen nach Anwendung eine größere Infektionsgefahr, daher sollte in dieser Zeit besonders sorgfältig auf die Vermeidung von Infektionserkrankungen geachtet werden. Bei älteren Patienten oder Patienten mit begleitenden Herz- oder Lungenerkrankungen sollte die Einleitung einer Ocrelizumab-Therapie ggf. verschoben werden [137]. Die Schweizerische Multiple Sklerose Gesellschaft empfiehlt Ocrelizumab-Patienten in der Schweiz, die in einem Gebiet mit vielen SARS-CoV-2-Fällen leben, sich so weit wie möglich zu isolieren, um ihr Infektionsrisiko zu verringern, und den Beginn einer Ocrelizumab-Therapie sorgsam abzuwägen [138]. Die Multiple Sclerosis International Federation rät Patienten unter Therapie, sich bei Verdacht auf, oder bei einer bestätigten Infektion mit SARS-CoV-2 nach vorheriger telefonischer Absprache, beim behandelnden Arzt vorzustellen. Das Risiko einer schwerwiegenden SARS-CoV-2Infektion wird unter Glatirameracetat, Interferon- $\beta$ oder Natalizumab als am geringsten eingeschätzt [139]. Eine verzögerte Ocrelizumab-Gabe kann auch aus Sicht des Multiple Sclerosis Trust und der Association of British Neurologists erwogen werden, um ein Infektionsrisiko $\mathrm{zu}$ reduzieren $[140,141]$.

Um Infektionskrankheiten vorzubeugen, sollten alle Patienten, die Ocrelizumab bekommen, vor Erstgabe nach den Empfehlungen der Ständigen Impfkommission (STIKO) für immunsupprimierte Patienten inkl. jährlicher Grippeschutz- und Pneumokokkenimpfung vakziniert werden. Zwischen Impfung und Ocrelizumab-Infusion sollte ein Abstand von 6 Wochen liegen, Lebendimpfungen sind unter Ocrelizumab kontraindiziert.

Ocrelizumab darf während derSchwangerschaft und Stillzeit nicht angewendet werden, weswegen eine wirksame Empfängnisverhütung unter Ocrelizumab für mindestens 12 Monate nach jeder Ocrelizumab-Gabe von der EMA empfohlen wird. Neue Daten legen nahe, dass dieser Sicherheitsabstand in $\mathrm{Zu}$ kunft möglicherweise verkürzt werden kann [85].

\section{Schlussfolgerung}

In der Zusammenschau hat man bei der Behandlung der Multiplen Sklerose in den letzten Jahren viel erreicht; die Zulassung von Ocrelizumab war ein weiterer wichtiger Schritt in die Richtung einer effektiven Behandlung von MS-Patienten. Dieser humanisierte anti-CD20monoklonale Antikörper, zweimal jährlich intravenös verabreicht, zählt zu den Hochwirksamkeitsmedikamenten zur Behandlung der schubförmigen MS mit einem bislang guten Sicherheitsprofil bei halbjährlicher Anwendung.

Hervorzuheben ist, dass Ocrelizumab das erste Medikament mit Wirksamkeit bei PPMS ist. Wichtig, wie bei jeder immunmodulierenden Substanz, sind eine rigorose Pharmakovigilanz, die Analyse von Registerdaten und die Ergebnisse von Phase-4-Studien (Beispiel die in Deutschland aktuell rekrutierende CONFIDENCE-Studie [64]). Weitere mechanistische Studien zur Aufklärung der Wirkweise der CD20 B-Zell-Depletion sind angezeigt.

\section{Korrespondenzadresse}

\section{Prof. Dr. Hans-Peter Hartung, FRCP}

Klinik für Neurologie, Universitätsklinikum

Düsseldorf, Medizinische Fakultät, HeinrichHeine-Universität

Moorenstraße 5, 40225 Düsseldorf,

Deutschland

hans-peter.hartung@uni-duesseldorf.de

Funding. Open Access funding provided by Projekt DEAL.

\section{Einhaltung ethischer Richtlinien}

Interessenkonflikt. J.Graf hat Kongress- und Fortbildungsunterstützung von Biogen, Merck Serono, Sanofi-Genzyme, Grifols sowie ein Forschungsstipendium von der Deutschen Forschungsgemeinschaft (Projektnummer 438899010) erhalten. P. Albrecht erhielt Forschungsförderung durch den Europäischen Fonds für Regionale Entwicklung (EFRE, FKZ 0801739) sowie Allergan, Biogen, Celgene, Ipsen, Merz, Merck,
Novartis, Roche, Sanofi-Genzyme sowie Honorare und Reisekostenunterstützung durch Allergan, Bayer Healthcare, Biogen, Celgene, Ipsen, Merck, Merz, Novartis, Roche, Sanofi-Genzyme und Teva. N. Goebels hat Forschungsförderung, Reisekostenunterstützung und/oder Honorare erhalten von BMBF, HHUForschungskommission, Progressive MS Alliance, Wellcome Trust, Biogen, Novartis, Roche und SanofiGenzyme. O. Aktas erhielt Forschungsförderung durch das Bundesministerium für Bildung und Forschung (BMBF, NationNMO im KKNMS, FKZ01GI1602B) sowie Bayer Healthcare, Biogen, Novartis, Sanofi-Genzyme und Teva sowie Honorare und Reisekostenunterstützung durch Almirall, Bayer Healthcare, Biogen, Celgene, Medimmune, Merck, Novartis, Roche, Sanofi-Genzyme, VielaBio und Teva. H.-P. Hartung hat Honorare erhalten für Tätigkeit in Steering und Data Monitoring Committees von Bayer Healthcare, Biogen Celgene Receptos, Geneuro, Medimmune, Merck, Novartis, Roche, Sanofi Genzyme, Teva, TG Therapeutics, VielaBio.

Für diesen Beitrag wurden von den Autoren keine Studien an Menschen oder Tieren durchgeführt. Für die aufgeführten Studien gelten die jeweils dort angegebenen ethischen Richtlinien.

Open Access. Dieser Artikel wird unter der Creative Commons Namensnennung 4.0 International Lizenz veröffentlicht, welche die Nutzung, Vervielfältigung, Bearbeitung, Verbreitung und Wiedergabe in jeglichem Medium und Format erlaubt, sofern Sie den/die ursprünglichen Autor(en) und die Quelle ordnungsgemäß nennen, einen Link zur Creative Commons Lizenz beifügen und angeben, ob Änderungen vorgenommen wurden.

Die in diesem Artikel enthaltenen Bilder und sonstiges Drittmaterial unterliegen ebenfalls der genannten Creative Commons Lizenz, sofern sich aus der Abbildungslegende nichts anderes ergibt. Sofern das betreffende Material nicht unter der genannten Creative Commons Lizenz steht und die betreffende Handlung nicht nach gesetzlichen Vorschriften erlaubt ist, ist für die oben aufgeführten Weiterverwendungen des $\mathrm{Ma}$ terials die Einwilligung des jeweiligen Rechteinhabers einzuholen.

Weitere Details zur Lizenz entnehmen Sie bitte der Lizenzinformation auf http://creativecommons.org/ licenses/by/4.0/deed.de.

\section{Literatur}

1. Thompson AJ, Baranzini SE, Geurts J, Hemmer B, Ciccarelli O (2018) Multiple sclerosis. Lancet 391:1622-1636. https://doi.org/10.1016/S01406736(18)30481-1

2. Lublin FD, Reingold SC, Cohen JA, Cutter GR, Sørensen PS, Thompson AJ et al (2014) Defining the clinical course of multiple sclerosis: the 2013 revisions. Neurology 83:278-286. https://doi.org/ 10.1212/WNL.0000000000000560

3. Lublin FD (2014) New multiple sclerosis phenotypic classification. Eur Neurol 72(Suppl 1):1-5. https:// doi.org/10.1159/000367614

4. Kinzel S, Weber MS (2016) B cell-directed therapeutics in multiple sclerosis: rationale and clinical evidence. CNS Drugs 30:1137-1148. https://doi.org/10.1007/s40263-016-0396-6

5. Gingele S, Skripuletz T, Jacobs R (2020) Role of CD20+ T cells in multiple sclerosis: implications 
for treatment with ocrelizumab. Neural Regen Res 15:663-664. https://doi.org/10.4103/1673-5374. 266913

6. Beers SA, Chan CHT, French RR, Cragg MS, Glennie MJ (2010) CD20 as a target for therapeutic type I and II monoclonal antibodies. Semin Hematol 47:107-114. https://doi.org/10.1053/j. seminhematol.2010.01.001

7. Greenfield AL, Hauser SL (2018) B-cell therapy for multiple sclerosis: entering an era. Ann Neurol 83:13-26. https://doi.org/10.1002/ana.25119

8. Butler LA, Tam CS, Seymour JF (2017) Dancing partners at the ball: rational selection of next generation anti-CD20 antibodies for combination therapy of chronic lymphocytic leukemia in the novel agents era. Blood Rev 31:318-327. https:// doi.org/10.1016/j.blre.2017.05.002

9. Montalban X, Arnold DL, Weber MS, Staikov I, Piasecka-Stryczynska K, Willmer J et al (2019) Placebo-controlled trial of an oral BTK inhibitor in multiple sclerosis. N Engl J Med 380:2406-2417. https://doi.org/10.1056/NEJMoa1901981

10. Bar-Or A, Grove RA, Austin DJ, Tolson JM, VanMeter SA, Lewis EW et al (2018) Subcutaneous ofatumumab in patients with relapsing-remitting multiple sclerosis: The MIRROR study. Neurology 90:e1805-e1814. https://doi.org/10.1212/WNL. 0000000000005516

11. Hauser SL, Bar-Or A, Cohen J, Comi G, Correale J, Coyle PK, Cross AH, de Seze J, Montalban X, Selmaj K, Wiendl H, Goodyear A, Häring DA, Kerloeguen C, Tomic D, Willi R, Ramanathan K, Merschhemke M, Kappos L (2019) Efficacy and safety of ofatumumab versus teriflunomide in relapsing multiple sclerosis: results of the phase 3 ASCLEPIOS I and II trials. https:// onlinelibrary.ectrims-congress.eu/ectrims/2019/ stockholm/279581/stephen.hauser.efficacy.and. safety.of.ofatumumab.versus.teriflunomide.in. html.Zugegriffen: 30.01 .2020

12. Svenningsson $A$, Bergman J, Dring $A$, Vågberg $M$, Birgander R, LindqvistTetal (2015) Rapid depletion of $B$ lymphocytes by ultra-low-dose rituximab delivered intrathecally. Neurol Neuroimmunol Neuroinflamm 2:e79. https://doi.org/10.1212/ NXI.0000000000000079

13. Komori M, Lin YC, Cortese I, Blake A, Ohayon J, Cherup J et al (2016) Insufficient disease inhibition by intrathecal rituximab in progressive multiple sclerosis. AnnClin TransI Neurol 3:166-179. https:// doi.org/10.1002/acn3.293

14. Li R, Patterson KR, Bar-Or A (2018) Reassessing $B$ cell contributions in multiple sclerosis. Nat Immunol 19:696-707. https://doi.org/10.1038/ s41590-018-0135-x

15. Monson NL, Cravens PD, Frohman EM, Hawker K, Racke MK (2005) Effect of rituximab on the peripheral blood and cerebrospinal fluid B cells in patients with primary progressive multiple sclerosis. Arch Neurol 62:258-264. https://doi.org/ 10.1001/archneur.62.2.258

16. Cross AH, Stark JL, Lauber J, Ramsbottom MJ, Lyons J-A (2006) Rituximab reduces B cells and $T$ cells in cerebrospinal fluid of multiple sclerosis patients. J Neuroimmunol 180:63-70. https://doi. org/10.1016/j.jneuroim.2006.06.029

17. Stüve O, Cepok S, Elias B, Saleh A, Hartung H-P, Hemmer B, Kieseier BC (2005) Clinical stabilization and effective B-lymphocyte depletion in the cerebrospinal fluid and peripheral blood of a patient with fulminant relapsing-remitting multiple sclerosis. Arch Neurol 62:1620-1623. https://doi.org/10.1001/archneur.62.10.1620
18. Leussink VI, Lehmann HC, Meyer zu Hörste G, Hartung H-P, Stüve O, Kieseier BC (2008) Rituximab induces clinical stabilization in a patient with fulminant multiple sclerosis not responding to natalizumab. Evidence for disease heterogeneity. J Neurol 255:1436-1438. https://doi.org/10.1007/ s00415-008-0956-X

19. Stüve O, Leussink VI, Fröhlich R, Hemmer $B$ Hartung H-P, Menge T, Kieseier BC (2009) Longterm B-lymphocyte depletion with rituximab in patients with relapsing-remitting multiple sclerosis. Arch Neurol 66:259-261. https://doi.org/ 10.1001/archneurol.2008.551

20. Bar-Or A, Calabresi PAJ, Arnold D, Arnlod D, Markowitz C, Shafer S et al (2008) Rituximab in relapsing-remitting multiple sclerosis: A 72-week, open-label, phase I trial. Ann Neurol 63:395-400. https://doi.org/10.1002/ana.21363

21. Hauser SL, Waubant E, Arnold DL, Vollmer T, Antel J, Fox RJ et al (2008) B-cell depletion with rituximabin relapsing-remitting multiple sclerosis. N Engl J Med 358:676-688. https://doi.org/10. 1056/NEJMoa0706383

22. Hawker K, O'Connor P, Freedman MS, Calabresi PA Antel J, Simon J et al (2009) Rituximab in patients with primary progressive multiplesclerosis: Results of a randomized double-blind placebo-controlled multicenter trial. Ann Neurol 66:460-471. https:// doi.org/10.1002/ana.21867

23. Hartung H-P, Aktas O (2009) Bleak prospects for primary progressive multiple sclerosis therapy: downs and downs, but a glimmer of hope. Ann Neurol 66:429-432. https://doi.org/10.1002/ana. 21880

24. Kappos L, Li D, Calabresi PA, O'Connor P, BarOr A, Barkhof $F$ et al (2011) Ocrelizumab in relapsing-remitting multiple sclerosis: a phase 2 , randomised, placebo-controlled, multicentre trial Lancet 378:1779-1787. https://doi.org/10.1016/ S0140-6736(11)61649-8

25. Hauser SL, Bar-Or A, Comi G, Giovannoni G, Hartung H-P, Hemmer B et al (2017) Ocrelizumab versus interferon beta-1a in relapsing multiple sclerosis. N Engl J Med 376:221-234. https://doi. org/10.1056/NEJMoa1601277

26. Montalban X, Hauser SL, Kappos L, Arnold DL, Bar-Or A, Comi G et al (2017) Ocrelizumab versus placebo in primary progressive multiple sclerosis. N Engl J Med 376:209-220. https://doi.org/10. 1056/NEJMoa1606468

27. Fox EJ, Markowitz C, Applebee A, Montalban X, Wolinsky JS, Belachew S et al (2018) Ocrelizumab reduces progression of upper extremity impairment in patients with primary progressive multiple sclerosis: findings from the phase III randomized ORATORIO trial. Mult Scler 24:1862-1870. https:// doi.org/10.1177/1352458518808189

28. Kappos L, Wolinsky JS, Giovannoni G, Arnold DL, Wang $\mathrm{Q}$, Bernasconi $\mathrm{C}$, Model F, Koendgen $\mathrm{H}$, Manfrini M, Belachew S, Hauser SL (2020) Progression independent of relapse activity in patients with typical relapsing multiple sclerosis: pooled analysis of 2 randomized clinical trials. JAMA Neurol. https://doi.org/10.1001/ jamaneurol.2020.1568

29. Nosadini M, Alper G, Riney CJ, Benson LA, Mohammad SS, Ramanathan S et al (2016) Rituximab monitoring and redosing in pediatric neuromyelitis optica spectrum disorder. Neurol Neuroimmunol Neuroinflamm 3:e188. https://doi. org/10.1212/NXI.0000000000000188

30. European Medical Agency (EMA) (2018) Ocrelizumab: Zusammenfassung der Merkmale des Arzneimittels. https://www.ema.europa. eu/en/documents/product-information/ocrevusepar-product-information_de.pdf. Zugegriffen: 01.02 .2020

31. Havrdová E, Arnold DL, Bar-Or A, Comi G, Hartung H-P, Kappos L et al (2018) No evidence of disease activity (NEDA) analysis by epochs in patients with relapsing multiple sclerosis treated with ocrelizumab vs interferon beta-1a. Mult Scler JExp TransI Clin 4:2055217318760642. https://doi. org/10.1177/2055217318760642

32. McCool R, Wilson K, Arber M, Fleetwood K, ToupinS, Thom Hetal (2019) Systematic review and network meta-analysis comparing ocrelizumab with other treatments for relapsing multiple sclerosis. Mult Scler Relat Disord 29:55-61. https://doi.org/10. 1016/j.msard.2018.12.040

33. Alcalá C, Gascón F, Pérez-Miralles F, Gil-Perotín S, Navarré A, Boscá I et al (2018) Efficacy and safety of rituximab in relapsing and progressive multiple sclerosis: a hospital-based study. J Neuro 265:1690-1697. https://doi.org/10.1007/s00415018-8899-3

34. Durozard $P$, Maarouf $A$, Boutiere $C$, Ruet $A$, Brochet B, Vukusic S et al (2018) Efficacy of rituximab in refractory RRMS. Mult Scler. https:// doi.org/10.1177/1352458518772748

35. Naegelin Y, Naegelin P, von Felten S, Lorscheider J, Sonder J, Uitdehaag BMJ et al (2019) Association of Rituximab treatment with disability progression among patients with secondary progressive multiple sclerosis. JAMA Neurol. https://doi.org/ 10.1001/jamaneurol.2018.4239

36. Turner B, Cree BAC, Kappos L, Montalban X, Papeix C, Wolinsky JS et al (2019) Ocrelizumab efficacy in subgroups of patients with relapsing multiple sclerosis. J Neurol. https://doi.org/10. 1007/s00415-019-09248-6

37. D'Amico $E$, Zanghì $A$, Chisari CG, Lo Fermo $S$, Toscano S, Arena S et al (2019) Effectiveness and safety of Rituximab in demyelinating diseases spectrum: an Italian experience. Mult Scler Relat Disord 27:324-326. https://doi.org/10.1016/j. msard.2018.09.041

38. Zecca C, Bovis F, Novi G, Capobianco M, Lanzillo R, Frau J et al (2019) Treatment of multiple sclerosis with rituximab: A multicentric Italian-Swiss experience. Mult Scler. https://doi.org/10.1177/ 1352458519872889

39. Salzer J, Svenningsson R, Alping P, Novakova $L$, Björck A, Fink $K$ et al (2016) Rituximab in multiple sclerosis: A retrospective observational study on safety and efficacy. Neurology 87:2074-2081. https://doi.org/10.1212/WNL. 0000000000003331

40. Spelman T, Frisell T, Piehl F, Hillert J (2018) Comparative effectiveness of rituximab relative to IFN- $\beta$ or glatiramer acetate in relapsingremitting MS from the Swedish MS registry. Mult Scler 24:1087-1095. https://doi.org/10.1177/ 1352458517713668

41. Granqvist M, Boremalm M, Poorghobad A Svenningsson A, Salzer J, Frisell T, Piehl F (2018) Comparative effectiveness of rituximab and other initial treatment choices for multiple sclerosis. JAMA Neurol 75:320-327. https://doi.org/10. 1001/jamaneurol.2017.4011

42. Cree BA (2018) Rituximab is an acceptable alternative to ocrelizumab for treating multiple sclerosis-commentary. MultScler 24:1161-1162. https://doi.org/10.1177/1352458518760717

43. Piehl F, Hillert J (2018) Rituximab is an acceptable alternative to ocrelizumab for treating multiple sclerosis-Yes. Mult Scler 24:1157-1159. https:// doi.org/10.1177/1352458518757930 
44. Wallin MT (2018) Rituximab is an acceptable alternative to ocrelizumab for treating multiple sclerosis-No. Mult Scler 24:1159-1161. https:// doi.org/10.1177/1352458518757931

45. Graf J, Aktas O, Rejdak K, Hartung H-P (2019) Monoclonal antibodies for multiple sclerosis: an update. BioDrugs 33:61-78. https://doi.org/10. 1007/s40259-018-0327-9

46. Ineichen BV, Moridi T, Granberg T, Piehl F (2019) Rituximab treatment for multiple sclerosis. Mult Scler. https://doi.org/10.1177/ 1352458519858604

47. WolinskyJS, Montalban X, Hauser SL, GiovannoniG, Vermersch P, Bernasconi C et al (2018) Evaluation of no evidence of progression or active disease (NEPAD) in patients with primary progressive multiple sclerosis in the ORATORIO trial. Ann Neurol. https://doi.org/10.1002/ana.25313

48. Barkhof F, Kappos L, Wolinsky JS, Li DKB, BarOr A, Hartung H-P et al (2019) Onset of clinical and MRI efficacy of ocrelizumab in relapsing multiple sclerosis. Neurology. https://doi.org/10. 1212/WNL.0000000000008189

49. MacMillan EL, Schubert JJ, Vavasour IM, Tam R, Rauscher A, Taylor C et al (2019) Magnetic resonance spectroscopy evidence for declining gliosis in MS patients treated with ocrelizumab versus interferon beta-1a. Mult Scler J Exp Transl Clin 5:2055217319879952. https://doi.org/10. $1177 / 2055217319879952$

50. Elliott C, Belachew S, Wolinsky JS, Hauser SL, Kappos L, Barkhof F et al (2019) Chronic white matter lesion activity predicts clinical progression in primary progressive multiple sclerosis. Brain 142:2787-2799. https://doi.org/10.1093/brain/ awz212

51. Hauser S, Kappos L, Montalban X, Koendgen H, Li C, Marcillat C et al (2018) Safety of ocrelizumab in multiple sclerosis: updated analysis in patients with relapsing and primary progressive multiple sclerosis (\$36.001). https://n neurology.org/content/90/15_Supplement/S36. 001. Zugegriffen: 10. Febr. 2020

52. Conte WL, Arndt N, Cipriani VP, Dellaria A, Javed A (2018) Reduction in ocrelizumab-induced infusion reactions by a modified premedication protocol. Mult Scler Relat Disord 27:397-399. https://doi. org/10.1016/j.msard.2018.11.027

53. Stahnke AM, Ocrelizumab HKM (2018) A new B-cell therapy for relapsing remitting and primary progressive multiple sclerosis. Ann Pharmacother 52:473-483. https://doi.org/10.1177/ 1060028017747635

54. Mayer L, Kappos L, Racke MK, Rammohan K, Traboulsee A, Hauser SL et al (2019) Ocrelizumab infusion experience in patients with relapsing and primary progressive multiple sclerosis: results from the phase 3 randomized OPERA I, OPERA II, and ORATORIO studies. Mult Scler Relat Disord. https:// doi.org/10.1016/j.msard.2019.01.044

55. Hauser SL, Kappos L, Montalban X, Hughes R, McNamara J, Pradhan A et al (2019) Safety of ocrelizumab in multiple sclerosis: updated analysis in patients with relapsing and primary progressive multiple sclerosis (P4.2-025). https:// n.neurology.org/content/92/15_Supplement/P4. 2-025.Zugegriffen: 10 . Febr. 2020

56. Ciardi MR, lannetta M, Zingaropoli MA, Salpini R, Aragri M, Annecca R et al (2019) Reactivation of hepatitis $B$ virus with immune-escape mutations after ocrelizumab treatment for multiple sclerosis. Open Forum Infect Dis 6:ofy356. https://doi.org/ 10.1093/ofid/ofy356
57. Nicolini LA, Canepa P, CaligiuriP, Mikulska M, NoviG, Viscoli C, Uccelli A (2019) Fulminant hepatitis associated with Echovirus 25 during treatment with ocrelizumab for multiple sclerosis. JAMA Neurol. https://doi.org/10.1001/jamaneurol.2019. 0522

58. Graf J, Leussink VI, Dehmel T, Ringelstein M, Goebels N, Adams O et al (2017) Infectious risk stratification in multiple sclerosis patients receiving immunotherapy. Ann Clin Transl Neurol 4:909-914. https://doi.org/10.1002/acn3.491

59. Cohen BA (2019) Late-onset neutropenia following ocrelizumab therapy for multiple sclerosis. Neurology 92:435-436. https://doi.org/10.1212/ WNL.0000000000006924

60. Zanetta C, Robotti M, Nozzolillo A, Sangalli F, Liberatore G, Nobile-Orazio Eetal (2019) Late onset absolute neutropenia associated with ocrelizumab treatment in multiple sclerosis: A case report and review of the literature. J Neurol Sci 409:116603. https://doi.org/10.1016/j.jns.2019.116603

61. Moreira Ferreira VF, Meredith D, Stankiewicz JM (2019) Tumefactive demyelination in a patient with relapsing-remitting MS on ocrelizumab. Neurol Neuroimmunol Neuroinflamm. https://doi.org/ 10.1212/NXI.0000000000000589

62. Multiple Sclerosis Association of America (2017) First case of PML with Ocrevus is reported-MSAA: the multiple sclerosis association of America. https://mymsaa.org/news/first-case-of-pmlwith-ocrevus-is-reported/. Zugegriffen: 5. Apr. 2019

63. Clifford DB, Gass A, Richert N, Tornatore C, Vermersch $\mathrm{P}$, Hughes R, Koendgen $\mathrm{H}$, Gold R (2019) Cases reported as progressive multifocal leukoencephalopathy in Ocrelizumab-treated patients with multiple sclerosis. https://onlinelibrary. ectrims-congress.eu/ectrims/2019/stockholm/ 279330/david.b.clifford.cases.reported.as. progressive.multifocal.leukoencephalopathy. html?f=listing\%3D0\%2Abrowseby\%3D8 \%2Asortby\%3D1\%2Asearch\%3Docrelizumab \%2Bpml.Zugegriffen: 10.03.2020

64. Dirks $P$, Zingler V, Leemhuis J, Berthold $H$, HiekeSchulz S, Wormser D, Ziemssen T (2020) Design of a non-interventional post-marketing study to assess the long-term safety and effectiveness of ocrelizumab in German real world multiple sclerosis cohorts-the CONFIDENCE study protocol. BMC Neurol 20:95. https://doi.org/10.1186/ s12883-020-01667-7

65. Ziemssen T, Berthold H, Dirks P, Evershed J, Gunzenhauser K, Leemhuis J Integration of ocrelizumab safety data from the German study CONFIDENCE into the global post-marketing safety studies MANUSCRIPT and VERISMO. 18.03.2020. https:// onlinelibrary.ectrims-congress.eu/ectrims/2018/ ectrims-2018/229464/tjalf.ziemssen.integration. of.ocrelizumab.safety.data.from.the.german. study.html.Zugegriffen: 18. März 2020

66. Focosi D, Tuccori M, Maggi F (2019) Progressive multifocal leukoencephalopathy and anti-CD20 monoclonal antibodies: what do we know after 20 years of rituximab. Rev Med Virol 29:e2077. https:// doi.org/10.1002/rmv.2077

67. Rommer PS, Dörner T, Freivogel K, Haas J, Kieseier BC, Kümpfel T et al (2016) Safety and clinical outcomes of rituximab treatment in patients with multiple sclerosis and neuromyelitis Optica: experience from a national Online registry (GRAID). J Neuroimmune Pharmacol 11:1-8. https://doi.org/10.1007/s11481-015-9646-5

68. Tallantyre EC, Whittam DH, Jolles S, Paling D, Constantinesecu C, Robertson NP, Jacob A (2018)
Secondary antibody deficiency: a complication of anti-CD20therapy forneuroinflammation.J Neuro 265:1115-1122. https://doi.org/10.1007/s00415018-8812-0

69. Christou EAA, Giardino G, Worth A, Ladomenou F (2017) Risk factors predisposing to the development of hypogammaglobulinemia and infections post-Rituximab. Int Rev Immunol 36:352-359. https://doi.org/10.1080/08830185.2017.1346092

70. Hallberg S, Boremalm M, Evertsson B, Lillvall $E$, Johansson F, Lycke J et al (2019) Risk of hypogammaglobulinemia in longterm treatment with rituximab in multiple sclerosis. https://onlinelibrary.ectrims-congress. eu/ectrims/2019/stockholm/279398/susanna. hallberg.risk.of.hypogammaglobulinemia.in. long-term.treatment.with.html. Zugegriffen: 23. März 2020

71. Luna G, Alping P, Burman J, Fink K, FogdellHahn A, Gunnarsson M et al (2019) Infection risks among patients with multiple sclerosis treated with fingolimod, natalizumab, rituximab, and Injectable therapies. JAMA Neurol.https://doi.org/ 10.1001/jamaneurol.2019.3365

72. Roche Pharma AG (2019) Important Information: Safety Update Ocrelizumab

73. Dudek MIR, Thies K, Kammenhuber S, Bösel J, Rösche J (2019) HSV-2-encephalitis in a patient with multiple sclerosis treated with ocrelizumab. J Neurol. https://doi.org/10.1007/s00415-01909391-0

74. Lattanzi S, Carlini G, Acciarri MC, Danni M, Silvestrini M (2019) Parvovirus B19 infection in a patient with multiple sclerosis treated with ocrelizumab. Acta Neurol Belg. https://doi.org/10. 1007/s13760-019-01227-y

75. Theriault M, Solomon AJ (2019) Two cases of meningitis associated with ocrelizumab therapy. Mult Scler Relat Disord 38:101866. https://doi.org/ 10.1016/j.msard.2019.101866

76. Novi G, Ivaldi F, Sbragia E, Mikulska M, Pesce G, Inglese $M$ et al (2020) Ocrelizumab does not impair B- and T-cell responses to primary VZV infection in a patient with MS. Neurol Neuroimmunol Neuroinflamm. https://doi.org/ 10.1212/NXI.0000000000000695

77. Faissner S, Schwake C, Gotzmann M, Mügge A, Schmidt S, Gold R (2020) Endocarditis following ocrelizumab in relapsing-remitting MS. Neurol Neuroimmunol Neuroinflamm. https://doi.org/ 10.1212/NXI.0000000000000680

78. Epstein DJ, Dunn J, Deresinski S (2018) Infectious complications of multiple sclerosis therapies: implications for screening, prophylaxis, and management. Open Forum Infect Dis 5:ofy174. https://doi.org/10.1093/ofid/ofy174

79. ZappuloE, Buonomo AR, Saccà F, Russo CV, Scotto R, Scalia $\mathrm{G}$ et al (2019) Incidence and predictive risk factors of infective events in patients with multiple sclerosis treated with agents targeting CD20 and CD52 surface antigens. Open Forum Infect Dis 6:ofz445. https://doi.org/10.1093/ofid/ofz445

80. Memon AB, Javed A, Caon C, Srivastawa S, Bao F, Bernitsas $E$ et al (2018) Long-term safety of rituximab induced peripheral B-cell depletion in autoimmune neurological diseases. PLoS ONE 13:e190425. https://doi.org/10.1371/journal. pone. 0190425

81. Abushouk Al, Ahmed H, Ismail A, Elmaraezy A, Badr AS, Gadelkarim M, Elnenny M (2017) Safety and efficacy of ocrelizumab in rheumatoid arthritis patients with an inadequate response to methotrexate or tumor necrosis factor inhibitors: a systematic review and meta-analysis. Rheuma- 
tol Int 37:1053-1064. https://doi.org/10.1007/ s00296-017-3675-8

82. Calabresi PA (2017) B-cell depletion-A frontier in monoclonal antibodies for multiple sclerosis. N Engl J Med 376:280-282. https://doi.org/10. 1056/NEJMe1614717

83. Jakimovski $D$, Weinstock-Guttman $B$, Ramanathan $M$, Kolb C, Hojnacki D, Minagar A, Zivadinov R (2017) Ocrelizumab: a B-cell depleting therapy for multiple sclerosis. Expert Opin Biol Ther 17:1163-1172. https://doi.org/10.1080/ 14712598.2017.1347632

84. Das G, Damotte V, Gelfand JM, Bevan C, Cree BAC, Do $L$ et al (2018) Rituximab before and during pregnancy: a systematic review, and a case series in MS and NMOSD. Neurol Neuroimmunol Neuroinflamm 5:e453. https://doi.org/10.1212/ NXI.0000000000000453

85. Oreja-Guevara C, Wray S, Buffels R, Zecevic D, Vukusic S (2019) Pregnancy outcomes in patients treated with ocrelizumab. https:// onlinelibrary.ectrims-congress.eu/ectrims/ 2019/stockholm/279140/celia.oreja-guevara. pregnancy.outcomes.in.patients.treated.with. ocrelizumab.html?f=listing\%3D3\%2Abrowseby \%3D8\%2Asortby\%3D1\%2Amedia\%3D1. Zugegriffen: 10. Febr. 2020

86. WormserD, EngelP,Hahn Ketal(2018)Ocrelizumab pregnancy registry to assess maternal, fetal, and infant outcomes in women with multiple sclerosis exposed to Ocrelizumab during pregnancy (DX50). https://ijmsc.org/doi/pdf/10.7224/1537-207320.s1.1.Zugegriffen: 10. Febr. 2020

87. Bergman J, Burman J, Gilthorpe JD, Zetterberg $\mathrm{H}$, Jiltsova E, Bergenheim T, Svenningsson A (2018) Intrathecal treatment trial of rituximab in progres sive MS: an open-label phase $1 \mathrm{~b}$ study. Neurology 91:e1893-e1901. https://doi.org/10.1212/WNL. 0000000000006500

88. Wekerle H (2017) B cells in multiple sclerosis. Autoimmunity 50:57-60. https://doi.org/10.1080/ 08916934.2017.1281914

89. Rahmanzadeh R, Weber MS, Brück W, Navardi S, Sahraian MA (2018) B cells in multiple sclerosis therapy-A comprehensive review. Acta Neurol Scand 137:544-556. https://doi.org/10.1111/ane. 12915

90. Sospedra M (2018) B cells in multiple sclerosis. Curr Opin Neurol 31:256-262. https://doi.org/10.1097/ WCO.000000000000563

91. Baecher-Allan C, Kaskow BJ, Weiner HL (2018) Multiple sclerosis: mechanisms and immunotherapy. Neuron 97:742-768. https://doi.org/10.1016/j. neuron.2018.01.021

92. Rommer PS, Milo R, Han MH, Satyanarayan S, Sellner J, Hauer L et al (2019) Immunological aspects of approved MS therapeutics. Front Immunol 10:1564. https://doi.org/10.3389/fimmu.2019. 01564

93. Ransohoff RM (2018) Immune-cell crosstalk in multiple sclerosis. Nature 563:194-195. https:// doi.org/10.1038/d41586-018-07063-z

94. Márquez AC, Horwitz MS (2015) The role of latently infected B cells in CNS autoimmunity. Front Immunol 6:544. https://doi.org/10.3389/fimmu. 2015.00544

95. Bar-Or A, Pender MP, Khanna R, Steinman L, Hartung H-P, Maniar T et al (2019) Epstein-Barr virus in multiple sclerosis: theory and emerging immunotherapies. Trends Mol Med. https://doi. org/10.1016/j.molmed.2019.11.003

96. Anthony DC, Dickens AM, Seneca N, Couch Y, Campbell S, Checa B et al (2014) Anti-CD20 inhibits T cell-mediated pathology and microgliosis in the ratbrain. Ann Clin TransI Neurol 1:659-669.https:// doi.org/10.1002/acn3.94

97. Chen D, Ireland SJ, Remington G, Alvarez E, Racke MK, Greenberg B et al (2016) CD40mediated NF-KB activation in B cells is increased in multiple sclerosis and modulated by therapeutics. J Immunol 197:4257-4265. https://doi.org/10. 4049/jimmunol.1600782

98. Haugen M, Frederiksen JL, Degn M (2014) B cell follicle-like structures in multiple sclerosiswith focus on the role of $B$ cell activating factor. J Neuroimmunol 273:1-7. https://doi.org/10. 1016/j.jneuroim.2014.05.010

99. Magliozzi R, Serafini B, Rosicarelli B, Chiappetta G Veroni C, Reynolds R, Aloisi F (2013) B-cell enrichment and Epstein-Barr virus infection in inflammatory cortical lesions in secondary progressive multiple sclerosis. J Neuropathol Exp Neurol 72:29-41. https://doi.org/10.1097/NEN. 0b013e31827bfc62

100. Lehmann-Horn K, KinzelS, Feldmann L, RadelfahrF, Hemmer B, Traffehn S et al (2014) Intrathecal antiCD20 efficiently depletes meningeal B cells in CNS autoimmunity. Ann Clin Transl Neurol 1:490-496. https://doi.org/10.1002/acn3.71

101. Palanichamy A, Apeltsin L, Kuo TC, Sirota M, Wang S, Pitts SJ et al (2014) Immunoglobulin class-switched $B$ cells form an active immune axis between CNS and periphery in multiple sclerosis Sci Transl Med 6:248r. https://doi.org/10.1126/ scitransImed.3008930

102. Mathias A, Perriard G, Canales M, Soneson C, Delorenzi M, Schluep M, Du Pasquier RA (2017) Increased ex vivo antigen presentation profile of $B$ cells in multiple sclerosis. Mult Scler 23:802-809. https://doi.org/10.1177/1352458516664210

103. Michel L, Touil H, Pikor NB, Gommerman JL, Prat A, Bar-Or A (2015) B cells in the multiple sclerosis central nervous system: trafficking and contribution to CNS-compartmentalized inflammation. Front Immunol 6:636. https://doi. org/10.3389/fimmu.2015.00636

104. Eggers EL, Michel BA, Wu H, Wang S-Z, Bevan CJ, Abounasr A et al (2017) Clonal relationships of CSF B cells in treatment-naive multiple sclerosis patients. JCI Insight. https://doi.org/10.1172/jci. insight. 92724

105. Lossius A, Tomescu-Baciu A, Holmøy T, Vedeler CA, Røsjø E, Lorentzen ÅR et al (2017) Selective intrathecal enrichment of G1m1-positive B cells in multiple sclerosis. Ann Clin Transl Neurol 4:756-761. https://doi.org/10.1002/acn3.451

106. Stein J, Xu Q, Jackson KC, Romm E, Wuest SC, Kosa P et al (2018) Intrathecal B cells in MS have significantly greater lymphangiogenic potential compared to B cells derived from non-MS subjects. Front Neurol 9:554. https://doi.org/10.3389/fneur. 2018.00554

107. Stern JNH, Yaari G, Vander Heiden JA, Church G, DonahueWF, Hintzen RQ etal (2014) Bcells populating the multiple sclerosis brain mature in the draining cervical lymph nodes. Sci Transl Med 6:248ra107. https://doi.org/10.1126/scitrans/med.3008879

108. Lisak RP, Nedelkoska L, Benjamins JA, Schalk D, Bealmear B, Touil $\mathrm{H}$ et al (2017) B cells from patients with multiple sclerosis induce cell death via apoptosis in neurons in vitro. J Neuroimmunol 309:88-99. https://doi.org/10.1016/j.jneuroim. 2017.05.004

109. Rivas JR, Ireland SJ, Chkheidze R, Rounds WH, Lim J, Johnson J et al (2017) Peripheral VH4+ plasmablasts demonstrate autoreactive $B$ cell expansion toward brain antigens in early multiple sclerosis patients. Acta Neuropathol 133:43-60. https://doi.org/10.1007/s00401-016-1627-0

110. Guerrier T, Labalette M, Launay D, Lee-Chang C, Outteryck O, Lefèvre G et al (2018) Proinflammatory B-cell profile in the early phases of MS predicts an active disease. Neurol Neuroimmunol Neuroinflamm 5:e431. https://doi.org/10.1212/ NXI.0000000000000431

111. Shen P, Fillatreau S (2015) Antibody-independent functions of B cells: a focus on cytokines. Nat Rev Immunol 15:441-451. https://doi.org/10.1038/ nri3857

112. von Büdingen $\mathrm{H}-\mathrm{C}$, Palanichamy $A$, LehmannHorn K, Michel BA, Zamvil SS (2015) Update on the autoimmune pathology of multiple sclerosis: B-cells as disease-drivers and therapeutic targets. Eur Neurol 73:238-246. https://doi.org/10.1159/ 000377675

113. Rijvers L, Melief $M-J$, van der Vuurst de Vries RM, Stéphant $M$, van Langelaar J, Wierenga-Wolf AF et al (2018) The macrophage migration inhibitory factor pathway in human B cells is tightly controlled and dysregulated in multiple sclerosis. Eur J Immunol 48:1861-1871. https://doi.org/10. 1002/eji.201847623

114. Li R, RezkA, Miyazaki Y, Hilgenberg E, Touil H, Shen $P$ et al (2015) Proinflammatory GM-CSF-producing $B$ cells in multiple sclerosis and B cell depletion therapy. Sci Transl Med 7:310ra166. https://doi. org/10.1126/scitrans/med.aab4176

115. Wurth S, Kuenz B, Bsteh G, Ehling R, Di Pauli F, Hegen $\mathrm{H}$ et al (2017) Cerebrospinal fluid B cells and disease progression in multiple sclerosis-A longitudinal prospective study. PLoS ONE 12:e182462. https://doi.org/10.1371/journal.pone.0182462

116. Cree BAC, Bennett JL, Kim HJ, Weinshenker BG, Pittock SJ, Wingerchuk DM et al (2019) Inebilizumab for the treatment of neuromyelitis optica spectrum disorder (N-MOmentum): a doubleblind, randomised placebo-controlled phase $2 / 3$ trial. Lancet 394:1352-1363. https://doi.org/10. 1016/S0140-6736(19)31817-3

117. Halliley JL, Tipton CM, Liesveld J, Rosenberg AF, Darce J, Gregoretti IV et al (2015) Long-lived plasma cells are contained within the CD19()CD38(hi)CD138(+) subsetin human bonemarrow. Immunity 43:132-145. https://doi.org/10.1016/j. immuni.2015.06.016

118. Mei HE, Wirries I, Frölich D, Brisslert M, Giesecke C, Grün JR et al (2015) A unique population of IgGexpressing plasma cells lacking CD19 is enriched in human bone marrow. Blood 125:1739-1748. https://doi.org/10.1182/blood-2014-02-555169

119. SchuhE, BererK, Mulazzani M,FeilK, MeinlI,LahmH et al (2016) Features of human CD3+CD20+ T cells. J Immunol 197:1111-1117. https://doi.org/ 10.4049/jimmunol.1600089

120. Jelcic I, Al Nimer F, Wang J, Lentsch V, Planas R, Jelcic l et al (2018) Memory B cells activate brainhoming, autoreactive CD4+ T cells in multiple sclerosis. Cell 175:85-100.e23. https://doi.org/10. 1016/j.cell.2018.08.011

121. Fraussen J, Claes $N$, van Wijmeersch $B$, van Horssen J, Stinissen P, Hupperts R, Somers V (2016) B cells of multiple sclerosis patients induce autoreactive proinflammatory $T$ cell responses. Clin Immunol 173:124-132. https://doi.org/10. 1016/j.clim.2016.10.001

122. Ireland SJ, Guzman AA, Frohman EM, Monson NL (2016) B cells from relapsing remitting multiple sclerosis patients support neuro-antigen-specific Th17 responses. J Neuroimmunol 291:46-53. https://doi.org/10.1016/j.jneuroim.2015.11.022 
123. Machado-Santos J, Saji E, Tröscher AR, Paunovic M Liblau R, Gabriely G et al (2018) The compartmentalized inflammatory response in the multiple sclerosis brain is composed of tissue-residentCD8+ T lymphocytes and B cells. Brain 141:2066-2082. https://doi.org/10.1093/brain/awy151

124. Knier B, Hiltensperger M, Sie C, Aly L, Lepennetier G, Engleitner T et al (2018) Myeloid-derived suppressor cells control B cell accumulation in the central nervous system during autoimmunity. Nat Immunol 19:1341-1351. https://doi.org/10.1038/ s41590-018-0237-5

125. Hohlfeld R, Dornmair K, Meinl E, Wekerle H (2016) The search for the target antigens of multiple sclerosis, part 2: CD8+Tcells, B cells, and antibodies in the focus of reverse-translational research. Lancet Neurol 15:317-331. https://doi.org/10. 1016/S1474-4422(15)00313-0

126. Gingele $S$, Jacobus $T L$, Konen $F F$, Hümmert MW Sühs K-W, Schwenkenbecher $\mathrm{P}$ et al (2018) Ocrelizumab depletes $\mathrm{CD} 20^{+} \mathrm{T}$ cells in multiple sclerosis patients. Cells. https://doi.org/10.3390/ cells8010012

127. Lovett-Racke $A E$, Gormley $M$, Liu $Y$, Yang $Y$, Graham C, Wray S et al (2019) B cell depletion with ublituximab reshapes the $T$ cell profile in multiple sclerosis patients. J Neuroimmunol 332:187-197. https://doi.org/10.1016/j.jneuroim.2019.04.017

128. Kompetenznetz Multiple Sklerose (2018) Qualitätshandbuch MS/NMOSD. https:// www.kompetenznetz-multiplesklerose.de/wpcontent/uploads/2018/11/KKNMS Qualit\%C3 \%A4tshandbuch-MS-NMOSD_2018_webfrei.pdf. Zugegriffen:03.02.2020

129. Buti M, Manzano ML, Morillas RM, García-Retortillo M, Martín L, Prieto M et al (2017) Randomized prospective study evaluating tenofovir disoproxil fumarate prophylaxis against hepatitis $B$ virus reactivation in anti-HBc-positive patients with rituximab-based regimens to treat hematologic malignancies: The Preblin study. PLoS ONE 12:e184550. https://doi.org/10.1371/journal. pone. 0184550

130. National Institute of Diabetes and Digestive and Kidney Diseases (2012) LiverTox: clinical and research information on drug-induced liver injury: ocrelizumab. National Institute of Diabetes and Digestive and Kidney Diseases, Bethesda

131. Klotz L, Havla J, Schwab N, Hohlfeld R, Barnett $M$, Reddel S, Wiendl H (2019) Risks and risk management in modern multiple sclerosis immunotherapeutic treatment. Ther Adv Neurol Disord 12:1756286419836571. https://doi.org/10 $1177 / 1756286419836571$

132. Derfuss $T$, Weber MS, Hughes $R$, Wang Q, Sauter A, Koendgen $\mathrm{H}$, Hauser SL, Bar-Or A, Hartung H-P (2020) Serum immunoglobulin levels and risk of serious infections in the pivotal Phase III trials of ocrelizumab in multiple sclerosis and their openlabel extensions ECTRIMS Online Library. Sep 11 2019; 279399. https://onlinelibrary.ectrimscongress.eu/ectrims/2019/stockholm/279399/ tobias.derfuss.serum.immunoglobulin.levels.and. risk.of.serious.infecti.Zugegriffen: 12. März 2020

133. Rovira À, Wattjes MP, Tintoré $M$, Tur C, Yousry TA, Sormani MP et al (2015) Evidence-based guidelines: MAGNIMS consensus guidelines on the use of $\mathrm{MRI}$ in multiple sclerosis-clinical implementation in the diagnostic process. Nat Rev Neurol 11:471-482. https://doi.org/10.1038/nrneurol. 2015.106

134. Auguste P, Colquitt J, Connock M, Loveman E, Court R, Ciccarelli O et al (2020) Ocrelizumab for treating patients with primary progressive multiple sclerosis: an evidence review group perspective of a NICE single technology appraisal. PharmacoEconomics. https://doi.org/10.1007/ s40273-020-00889-4

135. DMSG (Hrsg) (2020) Empfehlungen für Multiple Sklerose-Erkrankte zum Thema Corona-Virus/DMSG - Multiple Sklerose. https://www.dmsg.de/multiple-sklerosenews/dmsg-aktuell/news-article/News/ detail/empfehlungen-fuer-multiple-skleroseerkrankte-zum-thema-corona-virus/?no cache $=1 \&$ cHash $=1$ f 45 cc65 7 79272dae37d $6 \mathrm{e}$ 2827278143. Zugegriffen: 12. März 2020

136. Ellrichmann G, Bolz J, Peschke M, Duscha A, Hellwig K, Lee D-H et al (2019) Peripheral CD19+ $B$-cell counts and infusion intervals as a surrogate for long-term B-cell depleting therapy in multiple sclerosis and neuromyelitis optica/neuromyelitis optica spectrum disorders. J Neurol 266:57-67. https://doi.org/10.1007/s00415-018-9092-4

137. Kompetenznetz Multiple Sklerose (2020) Coronavirus SARS-CoV-2: Hinweise zur Anwendung von MS-Immuntherapeutika. https://www.kompetenznetz-multiplesklerose. de/coronavirus-sars-cov-2-hinweise-zuranwendung-von-ms-immuntherapeutika/. Zugegriffen: 17. März 2020

138. Schweizerische Multiple Sklerose Gesellschaft (Hrsg) (2020) COVID-19: Globale Empfehlung für MS-Betroffene. https://www. multiplesklerose.ch/de/aktuelles/detail/globalecovid-19-empfehlung-fuer-ms-betroffene/. Zugegriffen: 17. März 2020

139. MS International Federation (2020) The coronavirus and MS - global advice. https://www.msif. org/news/2020/02/10/the-coronavirus-and-mswhat-you-need-to-know/. Zugegriffen: 17. März 2020

140. MS Trust (Hrsg) (2020) Update on coronavirus COVID-19 and multiple sclerosis. https://www. mstrust.org.uk/news/update-coronavirus-covid19-and-multiple-sclerosis. Zugegriffen: 17. März 2020

141. Association of British Neurologists (2020) $A B N$ guidance on the use of disease-modifying therapies in multiple sclerosis in response to the threat of $A$ coronavirus epidemic. https://cdn.ymaws.com/www.theabn. org/resource/collection/6750BAE6-4CBC-4DDBA684-116E03BFE634/ABN Guidance on DMTs for_MS_and_COVID19_APPROVED_11_March. pdf.Zugegriffen: 17. März 2020
Sehbehinderte sollen durch Elektrostimulationen besser sehen

Forschende aus sieben europäischen Institutionen untersuchen, wie sich das Sehvermögen von Blinden durch elektrische Gehirnstimulationen aktivieren lässt.

Das Team von Forschenden, bestehend aus Spezialist*Innen für Computer-, System- und klinische Neurowissenschaften, Werkstofftechnik, Mikrosystemdesign und Deep Learning aus sieben europäischen Universitäten und Institutionen ,möchte neue Technologien entwickeln, um die visuelle Wahrnehmung von Blinden mithilfe von elektrischen Gehirnstimulationen zu verbessern

Ziel ist, eine Neuroprothese für Blinde mit Tausenden von Elektroden zu konstruieren, die leicht, robust und gut tragbar ist und über Jahrzehnte hinweg effizient arbeitet. Neue Ansätze für die Stimulation der Gehirnzellen im visuellen Kortex und eine Schnittstelle mit hoher Elektrodenanzahl sollen entwickelt werden. Dazu braucht es dünne, flexible Sonden sowie neue, stabile Elektrodenbeschichtungen und neuartige Mikrochip-Methoden. Zudem müssen die Stimulationsströme an tausenden Elektroden kanalisiert und die neuronale Aktivität in den verschiedenen Gehirnschichten beobachtet werden.

Die künstlichen neuronalen Netzwerke sollen durch Deep Learning dazu trainiert werden, nur die wichtigen visuellen Informationen zu extrahieren, die durch die Kamera generiert werden. So können die Testpersonen Objekte und Gesichtsausdrücke besser erkennen und sich auch im ungewohnten Umfeld zurechtfinden. Dabei müssen die Aufnahmen der Prothesenkamera in Stimulationsmuster umgewandelt werden, welche die Neuronen so stimulieren, dass sie für den Sehbehinderten oder Blinden verständlich sind. Nur so können Neuronen die Signale verarbeiten und weitergeben. Gleichzeitig soll durch Eyetracking der Testpersonen rückgemeldet werden, welche Bilder noch nicht genau genug umgewandelt wurden.

Quelle: Universität Zürich, http://www.uzh.ch/ 